\title{
Serial Systemic Injections of Endotoxin (LPS) Elicit Neuroprotective Spinal Cord Microglia through IL-1- Dependent Cross Talk with Endothelial Cells
}

\author{
${ }^{\circledR}$ Camila M. Freria, ${ }^{1,3}{ }^{\circledR}$ Faith H. Brennan, ${ }^{1,2,3}{ }^{-}$David R. Sweet, ${ }^{1}$ Zhen Guan, ${ }^{1,2,3}{ }^{\circledR}$ Jodie C. Hall, ${ }^{1,2,3}$ \\ ${ }^{\circledR}$ Kristina A. Kigerl, ${ }^{1,2,3}$ Daniel P. Nemeth, ${ }^{4,6}{ }^{\circledR}$ Xiaoyu Liu, ${ }^{4,6}{ }^{\circledR}$ Steve Lacroix, ${ }^{5}$ Ning Quan, ${ }^{4,6}$ \\ and Phillip G. Popovich ${ }^{1,2,3,4}$ \\ ${ }^{1}$ Center for Brain and Spinal Cord Repair, The Ohio State University Wexner Medical Center, Columbus, Ohio 43210, ${ }^{2}$ The Belford Center for Spinal Cord \\ Injury, The Ohio State University Wexner Medical Center, Columbus, Ohio $43210,{ }^{3}$ Department of Neuroscience, The Ohio State University Wexner \\ Medical Center, Columbus, Ohio 43210, ${ }^{4}$ Institute for Behavioral Medicine Research, The Ohio State University College of Medicine, Columbus, \\ Ohio 43210, ${ }^{5}$ Axe neurosciences, Centre de recherche du Centre hospitalier universitaire (CHU) de Québec, and Département de médecine \\ moléculaire, Université Laval, Québec, Québec G1V 4G2, Canada, and ${ }^{6}$ Brain Institute, Florida Atlantic University, Jupiter, Florida 33458
}

Microglia are dynamic immunosurveillance cells in the CNS. Whether microglia are protective or pathologic is context dependent; the outcome varies as a function of time relative to the stimulus, activation state of neighboring cells in the microenvironment or within progression of a particular disease. Although brain microglia can be "primed" using bacterial lipopolysaccharide (LPS)/endotoxin, it is unknown whether LPS delivered systemically can also induce neuroprotective microglia in the spinal cord. Here, we show that serial systemic injections of LPS ( $1 \mathrm{mg} / \mathrm{kg}$, i.p., daily) for 4 consecutive days (LPSx4) consistently elicit a reactive spinal cord microglia response marked by dramatic morphologic changes, increased production of IL-1, and enhanced proliferation without triggering leukocyte recruitment or overt neuropathology. Following LPSx4, reactive microglia frequently contact spinal cord endothelial cells. Targeted ablation or selective expression of IL-1 and IL-1 receptor (IL-1R) in either microglia or endothelia reveal that IL-1-dependent signaling between these cells mediates microglia activation. Using a mouse model of ischemic spinal cord injury in male and female mice, we show that preoperative LPSx4 provides complete protection from ischemia-induced neuron loss and hindlimb paralysis. Neuroprotection is partly reversed by either pharmacological elimination of microglia or selective removal of IL-1R in microglia or endothelia. These data indicate that spinal cord microglia are amenable to therapeutic reprogramming via systemic manipulation and that this potential can be harnessed to protect the spinal cord from injury.

Key words: endothelial cells; IL-1; ischemia spinal cord injury; LPS; microglia; neuroprotection

Significance Statement

Data in this report indicate that a neuroprotective spinal cord microglia response can be triggered by daily systemic injections of LPS over a period of $4 \mathrm{~d}$ (LPSx4). The LPSx 4 regimen induces morphologic transformation and enhances proliferation of spinal cord microglia without causing neuropathology. Using advanced transgenic mouse technology, we show that IL-1-dependent microglia-endothelia cross talk is necessary for eliciting this spinal cord microglia phenotype and also for conferring optimal protection to spinal motor neurons from ischemic spinal cord injury (ISCI). Collectively, these novel data show that it is possible to consistently elicit spinal cord microglia via systemic delivery of inflammogens to achieve a therapeutically effective neuroprotective response against ISCI.

Received Jan. 14, 2020; revised Sep. 13, 2020; accepted Sep. 17, 2020.

Author contributions: C.M.F. and P.G.P. designed research; C.M.F., F.H.B., D.R.S., Z.G., J.C.H., and K.A.K. performed research; D.P.N., X.L., S.L., N.Q., and P.G.P. contributed unpublished reagents/analytic tools; C.M.F. and D.R.S. analyzed data; C.M.F. and P.G.P. wrote the paper. Center for Neural Repair, University of California San Diego, La Jolla, CA 92093.

The authors declare no competing financial interests.

This work is supported by the National Institutes of Health (Grants R01-NS-099532, R01-NS-083942, and R35-NS-111582 to P.G.P.), the Ray W. Poppleton Endowment (to P.G.P.), the Craig H. Neilsen Foundation (Grant 457267 to F.H.B.), and Wings for Life (to F.H.B.). We thank Andrey Reymar (Plexxikon) for providing PLX5622. We thank Dr. Mark Tuszynski (University of California, San Diego (UCSD) for support and access to the Keyence BZ-X700 fluorescence microscope and Zeiss LSM 880 Airyscan laser-scanning microscope. We also thank Dr. Imre Kovacs (UCSD) for assistance with the Gallyas silver staining technique.

D. Nemth's, X. Liu's, and N. Quan's present address: Brain Institute and Schmidt College of Medicine, Florida Atlantic University, Jupiter, FL 33458.

C. M. Freria's present address: Center for Neural Repair, University of California San Diego, La Jolla, CA 92093.

Correspondence should be addressed to Phillip G. Popovich at phillip.popovich@osumc.edu or Camila M. Freria at camilafreria@gmail.com.

https://doi.org/10.1523/JNEUROSCI.0131-20.2020

Copyright $\odot 2020$ the authors 


\section{Introduction}

Microglia are tissue-resident macrophages that play an essential role in regulating CNS homeostasis. When homeostasis is disrupted (e.g., injury, disease), the integration of temporally and spatially restricted microenvironmental cues by microglia produces phenotypically and functionally heterogeneous cell populations that can positively or negatively affect neuroinflammation, neuron survival, axon plasticity and growth, remyelination, and glial activation (Nimmerjahn et al., 2005; Gensel et al., 2015; Szalay et al., 2016; Keren-Shaul et al., 2017; Krasemann et al., 2017; Bellver-Landete et al., 2019; Lloyd et al., 2019). Since microglia comprise $\sim 10 \%$ of all CNS cells and are ubiquitous throughout the CNS parenchyma (Lawson et al., 1990), it would be advantageous if the benefits of reactive microglia could be enhanced to promote neuroprotection or plasticity and repair but without also provoking inflammatory pathology.

Activating microglia in this context is challenging since most forms of CNS injury or disease that activate microglia also cause overt tissue damage, often with loss of function. An exception to this rule may be the neuroactive effects of systemic lipopolysaccharide (LPS). Indeed, systemic LPS can activate brain microglia without causing overt damage to the CNS (Breder et al., 1994; Qin et al., 2007). Circulating LPS signals to the brain through circumventricular organs and then activates microglia by binding to CD14 and toll-like receptor (TLR4; Lacroix et al., 1998; Chen et al., 2012). TLR4 is a highly conserved pattern recognition receptor that activates nuclear factor- $\kappa \mathrm{B}(\mathrm{NF}-\kappa \mathrm{B})$ signaling and synthesis of IL-1, IL-6, TNF, IL-18, and IL-12 (Zhang and Ghosh, 2001). Activating this neuroinflammatory response in microglia can be destructive (Godbout et al., 2005; Qin et al., 2007); but when delivered at low doses, LPS can protect the brain from injury (Ahmed et al., 2000; Marsh et al., 2009a; Hickey et al., 2011; Stevens et al., 2011; Chen et al., 2012; Yang et al., 2014; Wendeln et al., 2018). Whether systemic LPS elicits a protective or destructive microglia phenotype is determined by the dose and timing of LPS administration (Hoogland et al., 2015; TorresEspín et al., 2018).

Intuitively, the spinal cord could be considered the morphologic extension of the brain; however, anatomic, molecular, and functional differences exist between these discrete $\mathrm{CNS}$ regions that may leave spinal neurons more vulnerable than brain neurons to immune-mediated damage (Zhang et al., 2014b). For example, compared with the blood-brain barrier, the blood-spinal cord barrier (BSCB) is more permeable, perhaps because of higher basal expression of transporter molecules (e.g., P-glycoprotein) and decreased expression of tight- and adhesion-junction proteins on spinal cord endothelia (e.g., occludins, cadherins; Bartanusz et al., 2011; Zhang and Gensel, 2014). These molecular differences likely explain why the magnitude of neuroinflammation in the injured spinal cord is greater than in the injured brain (Schnell et al., 1999a, b; Batchelor et al., 2008; Zhang and Gensel, 2014). Differences in metabolic activity of spinal motor neurons also increase their vulnerability to oxidative and excitotoxic damage compared with upper motor neurons (Panov et al., 2011). The spinal cord also lacks immune-interfacing regions like the brain choroid plexus, where circulating proteins and molecules (e.g., LPS), directly affect parenchymal cells, including microglia. Because of these differences between the brain and spinal cord, it is prudent to empirically determine how systemic LPS affects spinal cord microglia and their ability to respond to injury.

In this study, we tested the hypothesis that serial systemic injections of LPS over $4 \mathrm{~d}$ (LPSx4) would elicit neuroprotective spinal cord microglia. We show that LPSx4 causes consistent changes in spinal cord microglia morphology and enhances their proliferative capacity without causing neuron pathology. Using advanced transgenic approaches, we show that IL-1-dependent microglia-endothelia cross talk is necessary for triggering a neuroprotective spinal cord microglia response and that these cells can be engaged to prevent spinal motor neuron loss and neurologic impairment after ischemic spinal cord injury (ISCI). Collectively, these data show that the bidirectional communication between spinal cord microglia and endothelial cells can be coopted to protect motor neurons from injury or disease.

\section{Materials and Methods \\ Mice}

All surgical and postoperative care procedures were performed in accordance with The Ohio State University Institutional Animal Care and Use Committee. A total of 211 mice were used. Adult (8-10-week-old) male and female C57BL/6J [wild-type (WT)] mice were purchased from The Jackson Laboratory (RRID:IMSR_JAX:000664). Global IL-1 $\beta$ and IL- $1 \alpha$ knock-out (KO) mice were obtained from Y. Iwakura (University of Tokyo, Tokyo, Japan; Horai et al., 1998), while pIl-1 $\beta$-DsRed transgenic mice that have the DsRed fluorescence protein gene expressed under the control of the IL- $1 \beta$ promoter (pIl-1 $\beta$ ) were obtained from Akira Takashima (University of Toledo, Toledo, OH; Matsushima et al., 2010). All mouse lines were bred in-house at the Animal Facility of the CHUL Research Center and genotyped as described previously (Bastien et al., 2015). We also used advanced transgenics to explore the effect of microglia-specific or endothelial cell-specific loss of IL-1R1. The IIIr1 ${ }^{r / r}$ has a "restore" allele (r) in which a floxed disruption sequence was knocked into the intron between exon IX and X of the Il1r1 gene to prevent IL-1R1 transcription and translation (Liu et al., 2019). To selectively restore IL-1R1 in microglia (Cx3cr1-Cre $x$ Il1r1 ${ }^{r / r}$ mice) or endothelial cells (Tie2-Cre $x$ Illr $1^{r / r}$ mice), Il1 $11^{r / r}$ animals were crossed with mice expressing Cre recombinase driven by $\mathrm{Cx} 3 \mathrm{cr} 1$ [stock $\operatorname{Tg}(\mathrm{C} \times 3 \mathrm{cr} 1-\mathrm{Cre})$ MW126Gsat] or Tie2 (stock \#004128, The Jackson Laboratory), respectively. Ubiquitous deletion of the disruption sequence is indicated by a "globally restored" allele (Il1r1 ${ }^{G R / G R}$ mice) which tracks IL-1R1 mRNA using an IRES-Tdtomato sequence inserted into the Illrl allele, thus acting as an IL-1R1 reporter (Liu et al., 2015). We also used $I l 1 r^{f / f}$ mice (obtained from Randy Blakely, Florida Atlantic University), wherein the Il1rl gene is floxed upstream of exon three and downstream of exon 4. These mice were crossed with $\mathrm{C} \times 3 \mathrm{cr} 1 \mathrm{Cre}$ mice and Tie2Cre mice to generate mice that do not express microglial IL-1R1 (Cx3cr1-Cre-Il1r1 fiff $)$ or endothelial IL-1R1 (Tie2-Cre-Il1r $1^{f / f}$ ), respectively. Mice were age- and weight-matched within experiments. Animals were housed under conventional conditions on a $12 \mathrm{~h}$ light/dark cycle with ad libitum access to food and water.

\section{In vivo manipulations}

Systemic LPS. To establish an LPS dosing paradigm required to activate spinal microglia, we first injected $I l 1 r 1^{\mathrm{GR} / \mathrm{GR}}$ and C57BL/6 mice with either one, two, three, or four consecutive daily doses of $1 \mathrm{mg} / \mathrm{kg}$ intraperitoneal LPS (Escherichia coli, serotype 055:B5, Sigma-Aldrich) or sterile saline. Body weights were recorded daily to confirm LPS bioactivity. After determining that four consecutive doses of LPS (LPSx4) triggered maximum microglia reactivity, we used LPSx4 or control injections [PBS daily for 4 consecutive days $(\mathrm{PBS} x 4)$ ] for subsequent studies.

$B r d U$. To label proliferating cells, mice were injected with the thymidine analog, bromodeoxyuridine (BrdU; $50 \mathrm{mg} / \mathrm{kg}$, i.p., in $0.9 \%$ saline; catalog \#10280879001, Sigma-Aldrich) daily for $4 \mathrm{~d}$, immediately after receiving LPS or PBS injection.

Microglia depletion. A colony-stimulating factor 1 receptor (CSF1R)antagonist, PLX5622 (PLX; 1200 mg/kg chow, p.o.; 290 ppm, Plexxikon, Research Diets) was used to pharmacologically deplete microglia. PLX is an orally bioavailable, blood-CNS-permeable compound that specifically inhibits CSF1R tyrosine kinase activity with 50 -fold selectivity over four related kinases (Dagher et al., 2015). Animals were randomly assigned to cages then cages were randomly assigned to a diet. Animals within a 
Table 1. Antibodies used for immunohistochemistry

\begin{tabular}{|c|c|c|c|}
\hline Antigen & Host, dilution & RRID & Vendor, catalog \# \\
\hline \multicolumn{4}{|l|}{ Primary antibodies } \\
\hline BrdU & Sheep (biotinylated), 1:200 & AB_302944 & Abcam, ab2284 \\
\hline CD11b & Rat, 1:300 & $A B \_321293$ & Serotec, MCA74G \\
\hline CD31 & Rat, 1:500 & AB_394816 & BD Pharmingen, 553370 \\
\hline Cleaved caspase-3 & Rabbit, 1:300 & $A B \_2341188$ & Cell Signaling Technology, 9661S \\
\hline Fibrinogen & Goat, 1:200 & AB_2861203 & Cappel Research Reagents, 55714 \\
\hline GFAP & Rabbit, 1:1000 & AB_10013382 & Agilent, Z0334 \\
\hline $\mid \mathrm{BA} 1$ & Rabbit, 1:1000 & $A B \_839504$ & Wako, 019-19741 \\
\hline LC3 (APG8) & Mouse, 1:300 & AB_2137696 & ABGent, AM1800a \\
\hline NeuN & Rabbit, 1:1000 & AB_10711153 & Abcam, ab104225 \\
\hline NeuN & Guinea-pig, 1:300 & AB_11205592 & Millipore, ABN90 \\
\hline NG2 & Rabbit, 1:200 & AB_2276877 & US Biological, C5067-70D \\
\hline P2RY12 & Rabbit, 1:1000 & AB_2298886 & Anaspec, AS-55043A \\
\hline RFP & Rabbit, 1:1000 & AB_2209751 & Rockland, 600-401-379 \\
\hline \multicolumn{4}{|l|}{ Secondary antibodies } \\
\hline Rabbit IgG Alexa Fluor 488 & Goat, 1:1000 & $A B \_2576217$ & Thermo Fisher Scientific, A-11034 \\
\hline Rabbit IgG Alexa Fluor 546 & Goat, 1:1000 & AB_2534093 & Thermo Fisher Scientific, A-11035 \\
\hline Rabbit IgG Alexa Fluor 633 & Goat, 1:1000 & $A B \_2535731$ & Thermo Fisher Scientific, A-21070 \\
\hline Rabbit lgG & Goat (biotinylated), 1:1000 & AB_954902 & Abcam, ab6720 \\
\hline Rabbit IgG Alexa Fluor 568 & Donkey, 1:500 & AB_2534017 & Thermo Fisher Scientific, A-10042 \\
\hline Rat IgG Alexa Fluor 488 & Goat, 1:1000 & AB_2534074 & Thermo Fisher Scientific, A-11006 \\
\hline Rat IgG Alexa Fluor 488 & Donkey, 1:500 & AB_141709 & Thermo Fisher Scientific, A-21208 \\
\hline Goat IgG Alexa Fluor 647 & Donkey, 1:500 & AB_141844 & Thermo Fisher Scientific, A-21447 \\
\hline Guinea pig IgG Alexa Fluor 647 & Donkey, 1:500 & AB_2340476 & The Jackson Laboratory, 706-605-148 \\
\hline Mouse IgG Alexa Fluor 568 & Donkey, 1:500 & AB_2534013 & Thermo Fisher Scientific, A-10037 \\
\hline
\end{tabular}

cage received the same diet (i.e., chow laced with PLX5622 or vehicle). Mice were fed diets for 2 weeks, then randomly assigned to receive LPSx 4 or PBSx 4 before undergoing ISCI. Mice remained on diets until the experimental end point ( $7 \mathrm{~d}$ post-ISCI).

\section{Tissue processing}

At the experimental endpoint, mice were injected with a mixture of ketamine $(120 \mathrm{mg} / \mathrm{kg})$ and xylazine $(15 \mathrm{mg} / \mathrm{kg})$ and then perfused intracardially with PBS $(0.1 \mathrm{M}, \mathrm{pH} 7.4)$ followed by $4 \%$ paraformaldehyde (PFA) in 0.1 M PBS. Spinal cords were dissected then postfixed overnight in 4\% PFA and then cryoprotected by immersion in $30 \%$ sucrose for $4 \mathrm{~d}$. Cervical, thoracic, and lumbar spinal cord segments were embedded in dry-ice cooled Tissue-Tek optimal cutting temperature medium (VWR). Coronal serial sections $(10 \mu \mathrm{m})$ were cut on a Microm cryostat (HM 505E), collected onto SuperFrost Plus slides (Thermo Fisher Scientific) then stored at $-20^{\circ} \mathrm{C}$. Thicker coronal sections $(30 \mu \mathrm{m})$ were collected as freefloating sections into $0.1 \mathrm{M}$ PBS.

\section{Immunohistochemistry}

Immunoperoxidase labeling. Spinal cord sections were rinsed in $0.1 \mathrm{M}$ PBS and endogenous peroxidases quenched using a 4:1 solution of methanol and $30 \% \mathrm{H}_{2} \mathrm{O}_{2}$ for $15 \mathrm{~min}$ in the dark. Sections were rinsed and blocked for nonspecific antigen binding using $4 \%$ BSA/0.1\% Triton X-100/PBS $\left(\mathrm{BP}^{+}\right)$for $1 \mathrm{~h}$. Sections were then incubated with primary antibody (Table 1 ) diluted in $\mathrm{BP}^{+}$overnight in humidified chambers at $4^{\circ} \mathrm{C}$. The next day, sections were rinsed three times in $0.1 \mathrm{M}$ PBS, then incubated with biotinylated secondary antibody (Table 1) diluted in $\mathrm{BP}^{+}$for $1 \mathrm{~h}$ at room temperature. Bound antibody was visualized using Elite-ABC reagent (Vector Laboratories) with 3,3'-diaminobenzidine as a substrate (Vector Laboratories Cat \#SK-4105). Sections were dehydrated through sequential 2 min incubations in $70,80,90$, and $100 \%$ ethanol solutions, followed by $3 \times 2 \mathrm{~min}$ incubations in Histoclear. Slides were coverslipped with Permount (Thermo Fisher Scientific).

Immunofluorescent labeling. Sections were rinsed in $0.1 \mathrm{M}$ PBS, blocked for $1 \mathrm{~h}$ in $\mathrm{BP}^{+}$, then incubated with primary antibodies (Table 1 ) overnight in humidified chambers at $4^{\circ} \mathrm{C}$. The next day, sections were rinsed $3 \times$ with $0.1 \mathrm{M}$ PBS, and then incubated in secondary antibodies for $1 \mathrm{~h}$ at room temperature (Table 1). After rinsing, slides were coverslipped with ImmuMount (Thermo Fisher Scientific). The same protocol was used for immunofluorescent staining of $30-\mu \mathrm{m}$-thick floating sections, except that all incubations were performed at room temperature on an orbital shaker. These sections were then gently transferred onto slides and coverslipped with ImmuMount. For BrdU staining, sections were treated with $2 \mathrm{~N} \mathrm{HCl}$ at $37^{\circ} \mathrm{C}$ for $25 \mathrm{~min}$ before primary antibody incubation to denature the DNA.

Nissl staining. Slides were rinsed in distilled water then submersed in $0.1 \%$ cresyl echt violet (ScyTek Laboratories) for $20 \mathrm{~min}$. Slides were then rinsed, dehydrated, and coverslipped with Permount (Thermo Fisher Scientific).

Gallyas method of silver staining. Silver impregnation of neuron cell bodies, axon terminals, and dendrites was performed using the method of Gallyas et al. (1980). Briefly, coronal spinal cord sections ( $30 \mu \mathrm{m}$ thickness) were pretreated with $1 \%$ sodium acetate at $56^{\circ} \mathrm{C}$ for $1 \mathrm{~h}$ followed by $10 \%$ alkaline hydroxylamine solution, $\mathrm{pH} 13$, for $5 \mathrm{~min}$ to suppress the staining of nondegenerated neurons/axons and to allow the hydrolysis of hydroxylamine. Slides were then washed in $1 \%$ acetic acid $3 \times$ for 1 min until sections became white opaque. For impregnation, sections were placed in a solution of $4 \%$ ferric nitrate and $20 \%$ silver nitrate for $20 \mathrm{~min}$ at $22^{\circ} \mathrm{C}$ until sections turned reddish yellow. After rinsing in $1 \%$ citric acid $4 \times$ for $2 \mathrm{~min}$ each, followed by $1 \%$ acetic acid for $5 \mathrm{~min}$, sections were immersed in physical developer solution, including ammonium nitrate, silver nitrate, and Tungstosilicic acid for 10 min. Finally, sections were washed in $1 \%$ acetic acid $3 \times$ for $5 \mathrm{~min}$ and dehydrated. Slides were coverslipped with DPX (SigmaAldrich).

\section{Imaging}

Immunoperoxidase and cresyl violet-stained images were captured using a Zeiss Axioplan 2 Imaging microscope (Carl Zeiss) or a Keyence BZX700. Fluorescent images were captured using a Zeiss Apotome Microscope with AxioCam MRm, a Keyence BZ-X700, a Zeiss LSM 880 Airyscan, or a Leica TCS SP8 laser-scanning confocal microscope. Fluorescent $z$-stack images were captured using a Zeiss LSM 880 Airyscan or Leica TCS SP8 laser-scanning confocal microscope at either $20 \times$ with $z$ intervals of $2 \mu \mathrm{m}$ over a $10 \mu \mathrm{m}$ distance, or at $40 \times / 1.2 \times$ oil with $z$ intervals of $0.50 \mu \mathrm{m}$ over a $30 \mu \mathrm{m}$ distance. Where appropriate, 


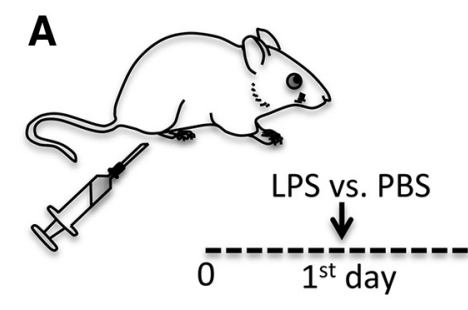

\section{Timeline}

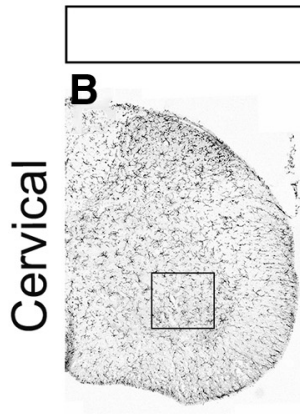

PBS
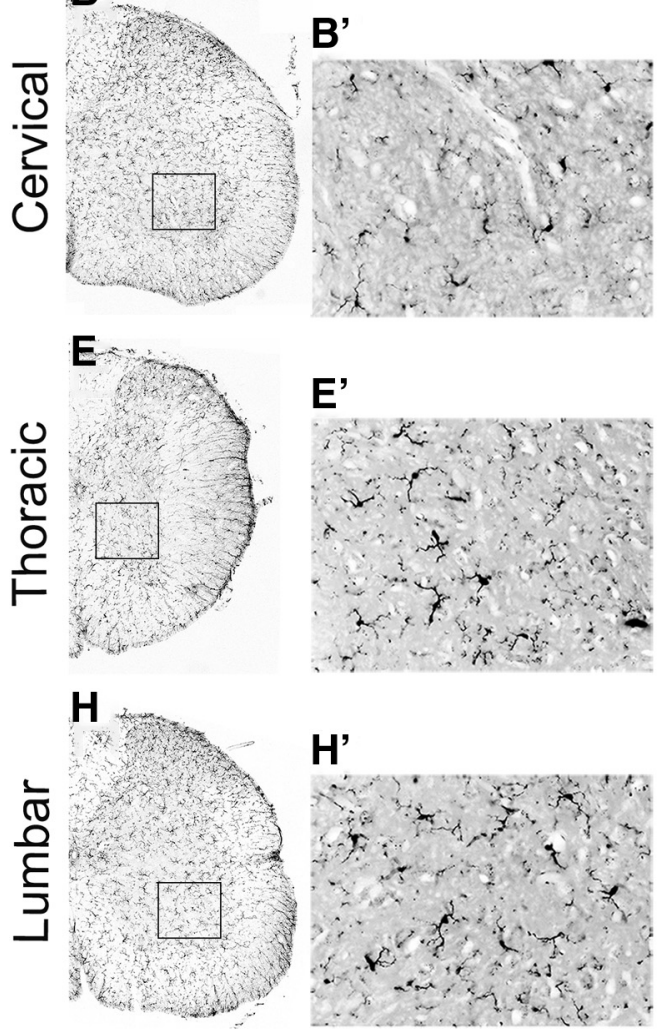
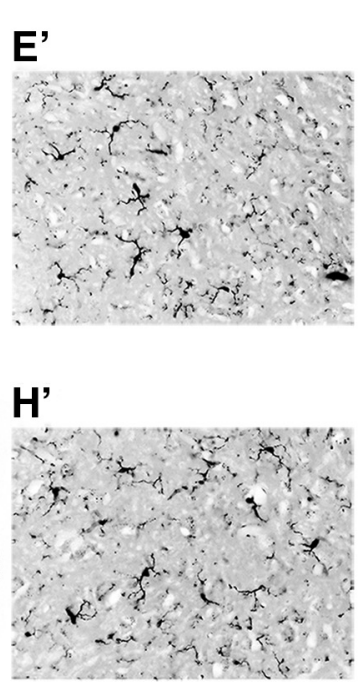

LPS vs. PBS

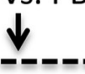

$2^{\text {nd }}$ day
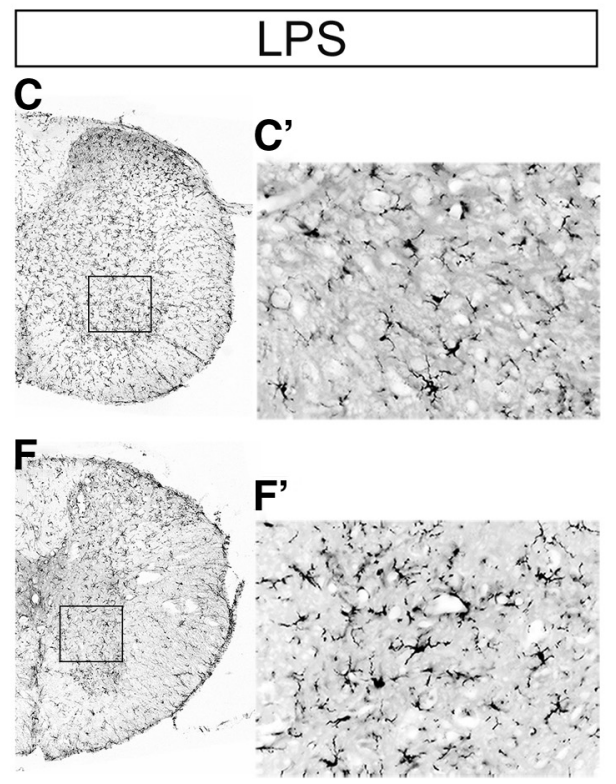

G
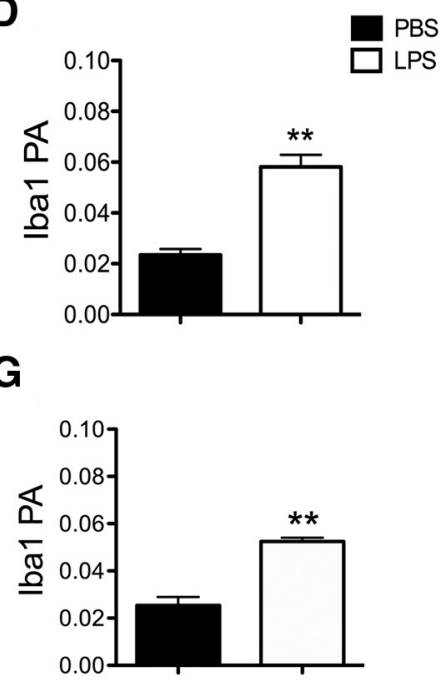

J

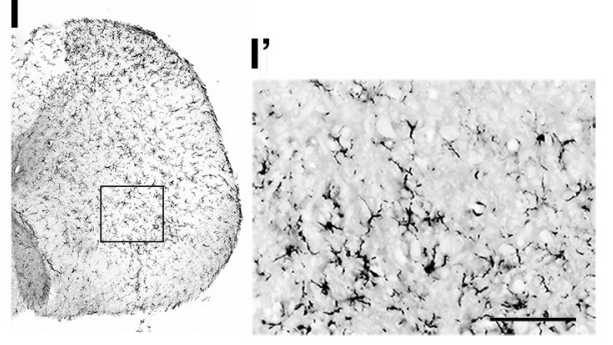

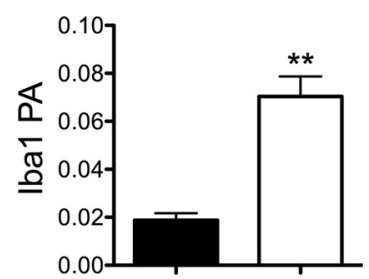

Figure 1. Four consecutive daily intraperitoneal injections of LPS (i.e., LPS 4 4) activate spinal cord microglia. $A$, Experimental timeline of daily LPS or PBS injections over $4 \mathrm{~d}$ and histologic analysis on the fifth day. $\boldsymbol{B}-\boldsymbol{C}^{\prime}, \boldsymbol{E}-\boldsymbol{F}^{\prime}, \boldsymbol{H}-\boldsymbol{I}^{\prime}$, Ramified microglia distribute throughout the cervical, thoracic, and lumbar spinal cord after PBSx4 injections $\left(\boldsymbol{B}, \boldsymbol{B}^{\prime}, \boldsymbol{E}, \boldsymbol{E}^{\prime}, \boldsymbol{H}, \boldsymbol{H}^{\prime}\right)$, but reactive microglia dominate the spinal cord of LPSX4 mice $\left(\boldsymbol{C}, \mathbf{C}^{\prime}, \boldsymbol{F}, \boldsymbol{F}^{\prime}, \boldsymbol{I}_{\mathbf{l}} \boldsymbol{I}^{\prime}\right) . \boldsymbol{D}, \mathbf{G}, \mathbf{J}$, Quantification of the PA of Iba1 immunoreactivity reveal significant differences between PBSX4 versus LPSX4 groups at all spinal cord levels. Graphs are representative of two independent experiments; data are the mean \pm SEM. Student's unpaired two-sided $t$ tests $(n=3 /$ group $) ; * * p<0.01$. Scale bar: $I^{\prime}$ (for $\left.\boldsymbol{B}^{\prime}, \boldsymbol{C}^{\prime}, \boldsymbol{E}^{\prime}, \boldsymbol{F}^{\prime}, \boldsymbol{H}^{\prime}, \boldsymbol{I}^{\prime}\right), 20 \mu \mathrm{m}$.

image montages were captured and tiles were auto-stitched in the $x y$ planes to generate a single image.

\section{Image analysis}

Proportional area. The proportional area (PA) occupied by positively stained microglia (Ibal-positive area/area of ROI) was quantified within spinal cord cross sections using MCID Elite image analysis software (Imaging Research). Fibrinogen PA was quantified in full spinal cross sections using ImageJ software (version 1.38d; NIH). For Iba ${ }^{+}$staining, two coronal sections for each spinal segment (cervical, thoracic, and lumbar) were quantified per mouse (Fig. 1, $n=3$ mice/group) and three coronal sections for each spinal segment (cervical, thoracic, and lumbar) were quantified per mouse (see Fig. $5 J-L$ ). In Figure 8, three coronal sections for lumbar spinal segment were quantified per mice $(n=4$ mice/ group; Fig. 8I,K,M,O,Q,S). In Figure 2, Iba1, NG2, and GFAP staining were quantified in four coronal sections from each mouse with ROIs focused in the L2-L4 ventral horn ( $n=3$ mice/group; Fig. $2 F, L, P)$. In some figures where microglia and neuron double labeling was required (Fig. 3, Figs. 9-11), microglia were labeled with CD11b instead of Iba1 because Ibal and NeuN primary antibodies were derived from the same species. For CD11b labeling, three coronal sections for lumbar spinal segment were quantified per mouse (see Fig. 10J, vehicle LPS, $n=5$ mice; PLX LPS, $n=3$ mice; see Fig. $11 D$, C57BL/6, $n=5$ mice; Cx3cr1-CreIllr $1^{f / f}, n=4$ mice; Tie2-Cre-Illr1 $1^{f / f}, n=2$ mice). To quantify spinal leveldependent changes in the accumulation of intraspinal fibrinogen, three coronal sections from each spinal segment (cervical, thoracic, and lumbar) were quantified (see Fig. 9H) in C57BL/6 mice after ISCI. To evaluate whether LPSx4 reduced fibrinogen leakage in ISCI mice, three sections from lumbar spinal cord were analyzed in each mouse in both PBS and LPSx4 groups (Fig. 9L, $n=3$ mice/group). Since the ischemic damage disrupts tissue architecture, including blood vessels, it was not possible to distinguish between intravascular and extravascular fibrinogen.

$\mathrm{BrdU}^{+}$cell counts. For mice that received 1, 2, 3, or 4 consecutive injections of LPS, ImageJ (version 1.38d; NIH) was used to quantify $\mathrm{BrdU}^{+}$cells. Cells were quantified in sections from L2, L3, and L4 spinal cord and averaged in each mouse ( $n=3$ mice/group). First, the image was converted to grayscale. An intensity threshold was set based on $\mathrm{BrdU}^{+}$staining, and a size criterion was applied to eliminate thresholded profiles $<2$ pixels. Profiles were automatically counted using the particle analyzer. The accuracy of automatic profile counts was confirmed 

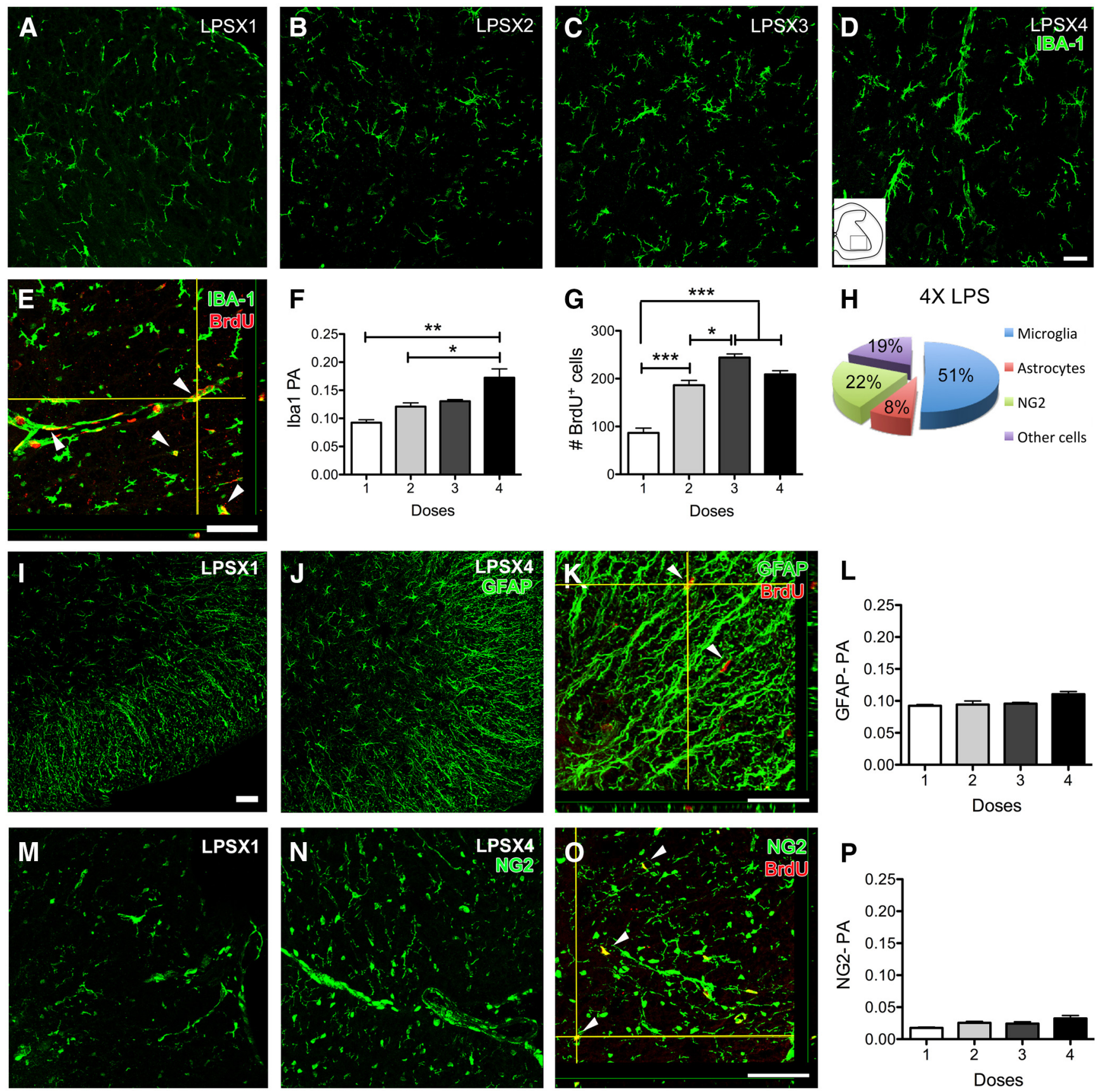

Figure 2. Four daily injections of LPS are required to achieve a proliferating reactive microglia phenotype. $A-E$, Consistent morphologic transformation of microglia requires four daily injections of LPS $(\boldsymbol{A}-\boldsymbol{D})$ and is preceded by an increase in the number of proliferating microglia $(\boldsymbol{E} ; \mathrm{Iba} 1 / \mathrm{green}$, BrdU/red). $\boldsymbol{F}$, Quantification of lba1 PA reveals significant morphologic changes in microglia after LPSX4 compared with mice receiving fewer LPS injections. G, Quantification of total numbers of BrdU ${ }^{+}$cells in spinal cord cross sections. $\boldsymbol{H}$, Pie graph illustrating the proportion of proliferating $\left(\mathrm{BrdU}^{+}\right)$astrocytes $\left(8 \%, \mathrm{GFAP}^{+}\right)$, NG2 glia $\left(22 \%, \mathrm{NG2}{ }^{+}\right)$, microglia $\left(51 \%, \mathrm{Iba}^{+}{ }^{+}\right)$, or unidentified cells $(19 \%)$ after LPSX4. $\mathbf{H}-\mathbf{L}$, Despite a slight increase in the numbers of proliferating astrocytes $(\boldsymbol{H}, \boldsymbol{K})$, astrocyte morphology $(\boldsymbol{I}, \boldsymbol{J}, \boldsymbol{L})$ is not changed by single or serial LPS injections. $\boldsymbol{M}-\boldsymbol{P}$, Similarly, systemic LPS has little effect on the proliferation or morphology of NG2 cells. Graphs are representative of a single experiment $(n=3$ mice/group); data are the mean \pm SEM. One-way ANOVA with Bonferroni's post hoc tests; $* p<0.05 ; * * p<0.01$; ***p $<0.001$. Scale bars: $\boldsymbol{D}$ (for $\boldsymbol{A}-\boldsymbol{D}$ ), $50 \mu \mathrm{m} ; \boldsymbol{E}, 50 \mu \mathrm{m} ; \boldsymbol{I}($ for $\boldsymbol{I}, \boldsymbol{J}, \boldsymbol{M}, \boldsymbol{N}$ ), $50 \mu \mathrm{m} ; \boldsymbol{K}, \mathbf{0}, 50 \mu \mathrm{m}$.

visually using digital masks that were overlaid onto the original histologic image. The proportion of $\mathrm{BrdU}^{+}$cells that were also $\mathrm{Ibal}^{+}$, $\mathrm{GFAP}^{+}$, or NG2 ${ }^{+}$was divided by the total number of $\mathrm{BrdU}^{+}$cells.

Neuron pathology. In Figure $3 A-D$, ImageJ was used to measure the average number and size of spinal cord ventral horn neurons. Cresyl violet-stained neurons were quantified within a $1500 \mu \mathrm{m}^{2}$ area of the ventral horn (lamina IX) in six randomly chosen cross sections cut at the L2-L4 spinal levels. See Figure 9, $S$ and $T$, for $\mathrm{LC}^{+} / \mathrm{NeuN}^{+}$double-labeled neurons that were counted within spinal lamina IX in three separate sections per animal. Each image was captured via confocal microscopy at $20 \times$ with $z$ intervals of $0.6 \mu \mathrm{m}$ over $20 \mu \mathrm{m}$ (see Fig. 9S,T, $n=4$ mice/group). See Figure 9, $Q$ and $R$, for the Gallyas method of silver staining was used to quantify degenerating neurons. Spinal cord neurons impregnated with silver staining were imaged at $20 \times$ then were counted in ventral horn lamina IX in six coronal sections per mouse (see Fig. $9 Q, R, n=6$ mice/group). The percentage of degenerated neurons was calculated as the total number of silver-stained neurons/total number of neurons within lamina IX. Nonstained neurons, visible by contrast (see Fig. 9Q, LPS image, dashed circles), were easily distinguished from glia based on their morphology, size, and location. 

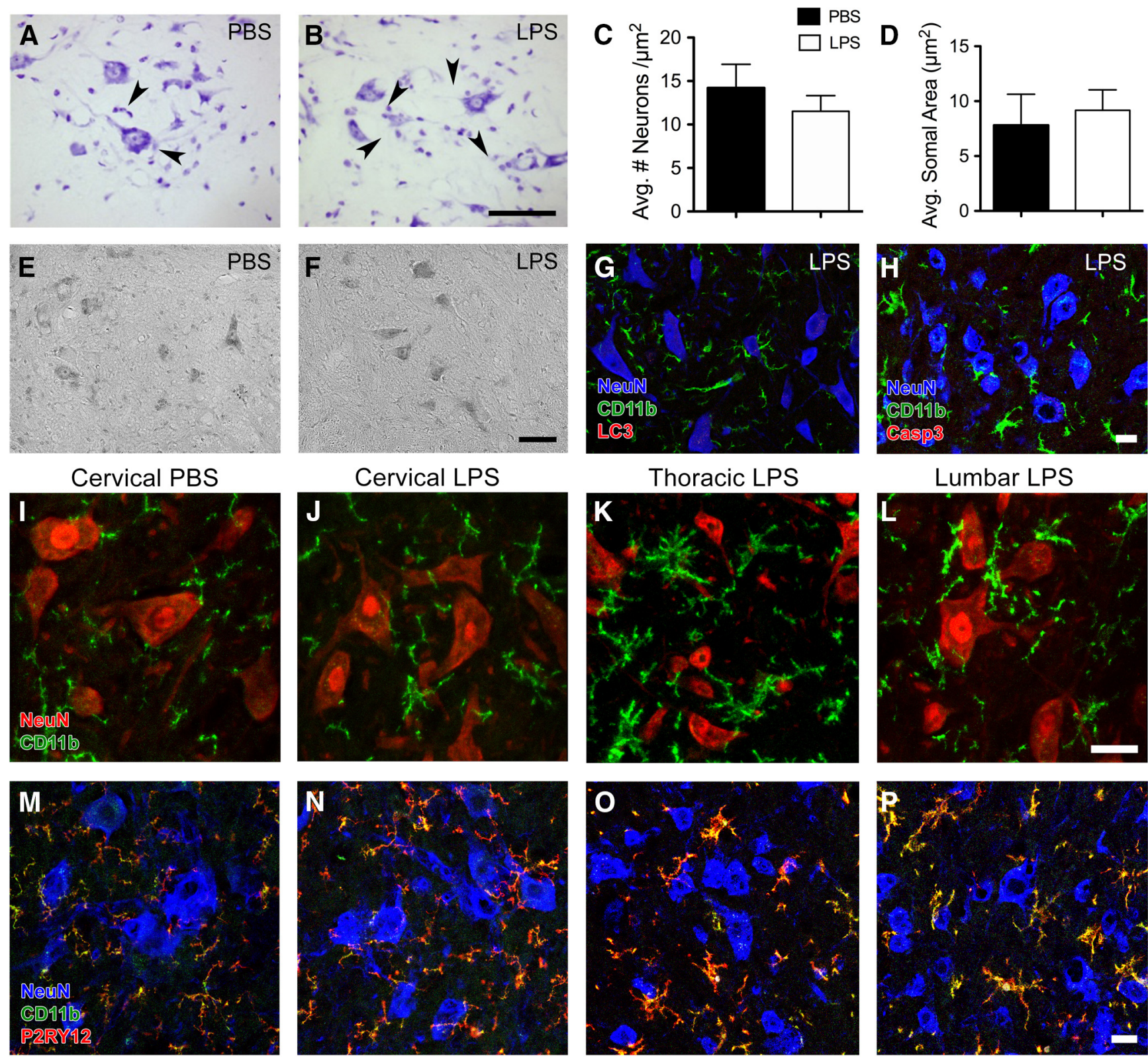

Figure 3. LPSX4 activates spinal cord microglia without causing neuronal pathology. $\boldsymbol{A}, \boldsymbol{B}$, Cresyl violet staining revealed that neither PBSx4 (A) nor LPSX4 (B) adversely affect spinal motor neuron survival. $\boldsymbol{C}, \boldsymbol{D}$, In lumbar spinal cord, the average number $(\boldsymbol{C})$ and size $(\boldsymbol{D})$ of motor neurons was identical between groups. $\boldsymbol{E}-\boldsymbol{H}$, To confirm that LPSX4 did not cause neuronal pathology, silver impregnation (Gallyas silver stain; $\boldsymbol{E}, \boldsymbol{F}$ ) and immunohistochemical stains for LC3 (an autophagy marker; $\boldsymbol{G}$ ), and cleaved caspase-3 antibodies (a marker for apoptotic cells; $\boldsymbol{H}$ ) were used. Regardless of the staining technique, no neuron or axonal pathology was detected in LPSX4 tissues. I-L, Immunofluorescent double-labeling for microglia (CD11b) and neurons (NeuN) revealed that perineuronal satellite cells $(\boldsymbol{A}, \boldsymbol{B}$, arrowheads), at all spinal levels in LPSX4 mice, are microglia. $\boldsymbol{M - P}$, Immunofluorescence triple labeling for NeuN, CD11b and the microglia-specific marker P2RY12 confirms that LPSX4 activates microglia but does not promote the recruitment of monocyte-derived macrophages; all CD11 ${ }^{+}$cells are also P2YR12 ${ }^{+}$. Data in $\boldsymbol{A}-\boldsymbol{D}(n=4$ mice/group; in $\boldsymbol{C}, \boldsymbol{D}$, data are the mean \pm SEM; Student's unpaired two-sided $t$ tests). Representative figures shown in $\boldsymbol{E}-\boldsymbol{P}$ were randomly captured from $n=3$ mice/group. Scale bars: $\boldsymbol{B}$ (for $\boldsymbol{A}, \boldsymbol{B}), 50 \mu \mathrm{m} ; \boldsymbol{F}$ (for $\boldsymbol{E}, \boldsymbol{F}), 50 \mu \mathrm{m} ; \boldsymbol{H}$ (for $\boldsymbol{G}, \boldsymbol{H}), 20 \mu \mathrm{m} ; \boldsymbol{L}$ (for $\boldsymbol{I}-\boldsymbol{L}), 20 \mu \mathrm{m} ; \boldsymbol{P}$ (for $\boldsymbol{M}-\boldsymbol{P}), 20 \mu \mathrm{m}$.

Quantifying microglial/spinal cord blood vessel intersections. The Sholl Analysis Fiji plugin was used to quantify the number of intersections between microglia ( $\mathrm{Ibal}^{+}$profiles) and blood vessels (TdTomato ${ }^{+}$ profiles) that had a length between 100 and $300 \mu \mathrm{m}$. Images were overlaid in a two-channel grayscale stack with adjusted threshold set to binarized. TdTomato ${ }^{+}$cells were chosen as center startup ROI determined as the blood vessel centroid where the straight-line tool was used to calculate interaction points along the line with $10 \mu \mathrm{m}$ interval concentric shells up to $100 \mu \mathrm{m}$ ending radius. The average number of $\mathrm{Ibal}^{+}$ intersections with $\mathrm{TdTomato}^{+}$profiles and maximum number of $\mathrm{Ibal}^{+}$ intersections with $\mathrm{TdTomato}^{+}$profiles was measured.

Microglia volume. The surface tool in Imaris (version 7.7.2; Bitplane) was used to create three-dimensional reconstructions of microglia in the ventral horns of the lumbar spinal cord in one section per mouse $(n=4)$. For this, the $\mathrm{Ibal}^{+}$channel was selected based on absolute intensity, with touching objects split. The selection was converted into a surface rendering and was color coded based on cell volume.

\section{RNA isolation, conversion, and quantitative PCR}

Mice were anesthetized with ketamine $(120 \mathrm{mg} / \mathrm{kg})$ and xylazine $(15 \mathrm{mg} /$ $\mathrm{kg}$ ) and then perfused intracardially with $0.1 \mathrm{M}$ PBS in DEPC (diethyl pyrocarbonate) water. Spinal cords were removed and homogenized in TRIzol (Thermo Fisher Scientific). After isolation, RNA concentration purity and concentration were measured via spectrophotometer (NanoDrop, Thermo Fisher Scientific). One microgram of RNA was 
converted to cDNA using M-MLV (Thermo Fisher Scientific) reverse transcriptase in a thermal cycler (Eppendorf). RNA profiles were analyzed using primers specific to the gene of interest and SYBR green master mix (Thermo Fisher Scientific). PCR was performed using an Applied Biosystems 7300 System (Thermo Fisher Scientific). Gene expression was extrapolated from standard curves generated concurrently for each gene using a control cDNA dilution series; expression was normalized to $18 \mathrm{~S}$ for each sample. Data were calculated using the $\Delta \Delta \mathrm{Ct}$ method (Schmittgen and Livak, 2008) and expressed as fold change from control. Primers used were as follows: IL- $1 \beta$ : forward, CAG-GCT-CCG-AGA-TGA-ACA-AC, and reverse, GGT-GGA-GAGCTT-TCA-GCT-CAT-AT; 18S: forward, TTC-GGA-ACT-GAG-GCCATG-AT, and reverse, TTT-CGC-TCT-GGT-CCG-TCT-TG.

\section{ISCI}

Mice were anesthetized by inhalation of $4 \%$ isoflurane driven by $100 \%$ $\mathrm{O}_{2}(800 \mathrm{ml} / \mathrm{min})$. During surgery, anesthesia was maintained by $1.5 \%$ isoflurane inhalation with $100 \mathrm{ml} / \mathrm{min}_{2}$ delivered via an endotracheal cannula and a mouse ventilator (Minivent model 845 Germany, Hugo Sachs Elektronik). Mouse body temperature was controlled between $33.5^{\circ} \mathrm{C}$ and $34.5^{\circ} \mathrm{C}$ using a temperature-controlled surgical platform (World Precision Instruments). ISCI was performed as described previously (Awad et al., 2010). Briefly, a ventral midline incision was made below the left forelimb and shoulder to expose the underlying rib cage. The muscle between the second and third rib was cut, exposing the lateral pleura. Retractors were used to open the incision and lateral hooks were used to completely expose the descending thoracic aorta. Spinal cord ischemia was induced by transient aortic cross-clamp at the level of the aortic arch or descending aorta. To ensure complete cross-clamp, the aorta was elevated, and two clips were placed across the vessel. Aortic cross clamp was maintained for $7.5-8 \mathrm{~min}$, and then the clip was removed for reperfusion. The rib cage, muscle, and overlying skin were closed using 6.0 polypropylene and 5.0 Dermalon nylon sutures. Animals were injected with $1 \mathrm{ml}$ of Ringer's saline solution and single housed into warmed cages at $36^{\circ} \mathrm{C}$. Hindlimb paralysis and seizures could be detected within 36-72 h after surgery. In total, of 103 animals that received an ISCI, 40 died during or shortly after surgery ( 22 because of seizures and another 18 to respiratory complications after removal of the endotracheal cannula). This mortality rate (39\%) is much higher than what we have reported previously ( $7 \%$; Awad et al., 2010) and is likely explained by superimposing the stress of surgery and ISCI onto mice with acute endotoxemia caused by LPSx 4 .

\section{Behavioral analysis}

Activity box. A subset of mice exposed to LPS and PBS were placed in an activity box (Animal Activity Meter Opto M3). In this task, vertical and horizontal sensors measured activity for $30 \mathrm{~min}$. Baseline measurements were obtained before injections. Mice were then tested at $4 \mathrm{~h}, 1,2$, 3 , and $4 \mathrm{~d}$ after injections. Outcome measures included total movement time, rest time, vertical activity time, and horizontal activity time. Data were compiled using AccuScan software.

Basso mouse scale for open-field locomotor analysis. Locomotor recovery from ischemic spinal cord injury was assessed in the open field using the Basso Mouse Scale (BMS; Basso et al., 2006). Two raters, blind to group assignment, rated locomotor performance over a $4 \mathrm{~min}$ period. During each session, raters evaluated hindlimb joint movement, weight support, plantar stepping, coordination, paw position, and trunk and tail control. Scores range from no hindlimb movement (0) to normal locomotor function (9). From the BMS data, a subscoring strategy was used to quantify improvements in stepping frequency, coordination, paw position, trunk stability, and tail position. BMS subscores were rated from 0 to 11, as described previously (Basso et al., 2006). BMS testing was performed beginning the first week after the onset of feeding PLX5622 diet or vehicle, then again 24, 48, and $72 \mathrm{~h}$ after PBS/LPS injections, and again at 4 and $7 \mathrm{~d}$ post-ISCI. Individual hindlimb scores were recorded and averaged for each mouse. After waiting at least $20 \mathrm{~min}$ after completing BMS scoring, animals that exhibited effective plantar stepping were selected for evaluation using TreadScan/beam-walking tasks.
TreadScan. TreadScan automatically detects coordinated activity in mice. The system consists of a treadmill (Clever Sys) with a transparent belt and a camera located under the track. For acclimation and baseline recordings, mice were placed on the treadmill at speeds of 15 and $10 \mathrm{~cm} /$ s. For recordings at 4 and $7 \mathrm{~d}$ after ISCI, mice with no signs of paralysis were placed on the treadmill at a speed of $10 \mathrm{~cm} / \mathrm{s}$ ( $n=9$ mice/group). The speed setting was chosen for easy performance gains after surgery and was used for all mice. Only runs with at least 20 consecutive steps were analyzed. The average run speed and regularity index were measured for all mice, where the regularity index is defined as the percentage of normal steps per step sequence.

Beam walking. The beam-walking apparatus consists of a horizontal rod, $182 \mathrm{~cm}$ in length and $1.2 \mathrm{~cm}$ in diameter, bounded by two walls. A mirror was placed at a $45^{\circ}$ angle below the horizontal rod such that the video camera could capture, in the same frame, a side view and also paw placement from below. Animals analyzed via TreadScan were also analyzed via beam walking. Because of the challenging conditions of this task, only a few animals were selected based on their ability to walk on a narrow beam without falling (vehicle-LPS, $n=6$; PLX-LPS, $n=4$ ). Each mouse performed at least three complete runs (distance, $\sim 58 \mathrm{~cm}$ of rod). Numbers of foot slips/foot falls (reported as "mistakes") were counted by an observer blinded to treatment group.

\section{Experimental design and statistical analysis}

All investigators involved in data acquisition or analysis were blind to group designation or experimental manipulation. Data were analyzed using GraphPad Prism 5 and are presented as the mean \pm SEM.

The experimental observations described in Figure 1 were independently replicated in two independent experiments by two different individuals. A "pilot" experiment, using $n=4$ mice/group, showed that LPSX 4 elicits consistent and robust changes in microglia morphology. Using those pilot data, a power analysis (two-tailed test $\alpha=0.05$; $\mathrm{SD}=$ 0.004 and desired power 0.80 ) revealed that $n=3$ mice/group could be used in replicate studies, including data in Figure 1, which were generated by an investigator different from the one that generated the pilot data. All subsequent experiments reported in Figures 2-8 (and see Fig. 11 ), for which measuring microglia morphology was a primary experimental outcome, were generated using groups sizes of $n=3-4$ mice/ group.

For each ISCI experiment, animals were randomized into treatment or control groups by an investigator that was not performing the ISCI surgery. Randomization was required for each day of surgery and because the ISCI surgery is time and labor intensive, no more than $n=6$ mice were randomized for surgery on any given day. Therefore, to complete a properly powered ISCI experiment, with behavioral analyses as a primary outcome measure, multiple days of surgery were required. Since mice from each experimental group are included on each day of surgery, an ISCI study technically represents a compilation of three to five multiple independent experiments. To generate the data in Figure 9 required $4 \mathrm{~d}$ of surgery ( $n=16$ total mice; $n=8$ /group). Data in Figure 10 were compiled from two independent experiments separated in time, each requiring $4-5 \mathrm{~d}$ to complete ISCI surgery on animals in each of the four different experimental or control groups. Overall, one mouse from each experimental or control group was randomly selected for ISCI on a given day ( $n=36$ mice total; vehicle + PBS and PLX + PBS, $n=5$ mice/group; vehicle + LPS and PLX + LPS, $n=13$ mice/group). After determining that LPSX 4 consistently elicited a reactive microglia response and that pharmacological depletion of microglia with PLX removed spinal microglia, data from the two independent experiments were combined. Note in the figure legends that final group sizes for TreadScan and beamwalking analysis vary from the above totals because not all mice achieved recovery thresholds that allowed them to be tested using these behavioral techniques (see details for each method above). For data that were generated from a single experiment where animal surgeries were performed over 6 consecutive days, see Figure 11. Each surgical day contained mice from every genetic background and relevant control or drug treatment groups. For data that were generated from $n=5 \mathrm{C} 57 \mathrm{BL} / 6 ; n=4 \mathrm{C} \times 3 \mathrm{cr} 1$ Cre-IllrI ${ }^{f / f} \mathrm{Cre}^{+}$; and $n=2$ Tie2-Cre-Il1r1 ${ }^{f / f} \mathrm{Cre}^{+}$see, see Figure 11. In 
the latter group, group size was reduced because two animals died after surgery.

All proportional area measurements (Figs. $1 D, G, J, 10 J)$, cell counts, or neuron area measurements (Figs. $3 C, D, 6 E, H, K, 9 K, O, S, 10 I, J)$ and RT-PCR data (Fig. $4 A$ ) in which two groups were compared, were analyzed using unpaired Student's two-tailed $t$ tests. All other anatomic data in which measurements were compared between three or more groups were analyzed using a one-way ANOVA with Bonferroni's post hoc tests. All behavioral data (Figs. $9 M, N, 10 K-L$ ) were analyzed using a two-way ANOVA with Bonferroni's post hoc tests. Statistical significance was determined at $p<0.05$.

\section{Results}

Repeat systemic injections of LPS (LPSx4) are required to elicit consistent morphologic transformation and proliferation of spinal cord microglia

Recent data indicate that injecting $1 \mathrm{mg} / \mathrm{kg}$ LPS into the peritoneal cavity daily for 4 consecutive days (i.e., LPSx4) causes consistent morphologic transformation of brain microglia. These "reactive" microglia protect the brain from traumatic injury and neurodegeneration (Chen et al., 2012; Wendeln et al., 2018). To determine whether the LPSx 4 protocol also activates spinal cord microglia, microglia morphology was quantified throughout the rostrocaudal extent of the spinal cord. Consistent with changes in brain (Chen et al., 2012), Iba1 ${ }^{+}$microglia in spinal cord gray matter and white matter of LPSx4-injected mice were consistently reactive, based on morphologic criteria, when compared with mice injected with PBSx4 (Fig. 1).

To determine whether the formation of reactive intraspinal microglia requires single or multiple systemic LPS injections, microglia morphology was evaluated after one, two, three, or four consecutive daily LPS injections. Only the LPSx4 paradigm was able to consistently elicit the reactive microglia phenotype (Fig. 2A-D,F). To determine whether enhanced proliferation of microglia contributes to the increased Ibal PA, we quantified the number of $\mathrm{BrdU}^{+}$cells. Unlike in the brain, where LPSx 4 fails to elicit microglia proliferation (Chen et al., 2012), proliferating spinal cord microglia were detected after only two LPS injections (Fig. 2G). Peak microglia proliferation occurred after three LPS injections. Most (51\%) proliferating cells were microglia (Fig. $2 H$ ). LPSx4 also triggered proliferation of $\mathrm{NG}^{+}$cells $(22 \%)$ and astrocytes (8\%). Other BrdU ${ }^{+}$cells were present $(19 \%)$ but did not colabel with any of these markers. There was minimal morphologic change in astrocytes and NG2 glia present within the same tissue sections, even with the LPSx4 paradigm (Fig. $2 I-L, M, P)$. Together, these data indicate that LPSx 4 induces a specific (and robust) reactive microglia phenotype marked by morphologic transformation and increased proliferation.

\section{LPSx4 does not cause neuropathology}

Systemic LPS causes transient hypothermia and a sickness-like behavior that persists throughout the $4 \mathrm{~d}$ evaluation period (data not shown). Importantly, in these mice, there is no evidence of leukocyte infiltration or neuropathology; neurons in the spinal cord ventral horn appear healthy, with no obvious change in cell number or cell size, and without evidence of chromatolysis (Fig. $3 A-D)$. Additional light and confocal microscopic techniques confirmed the absence of neuropathology. Specifically, neither the Gallyas silver stain (Fig. $3 E, F$ ), used to visualize degenerating neurons, nor antibodies specific for autophagic (LC3 ${ }^{+}$; Fig. $3 G$ ) or apoptotic (cleaved caspase- $3^{+}$; Fig. $3 H$ ) neurons, revealed any
A
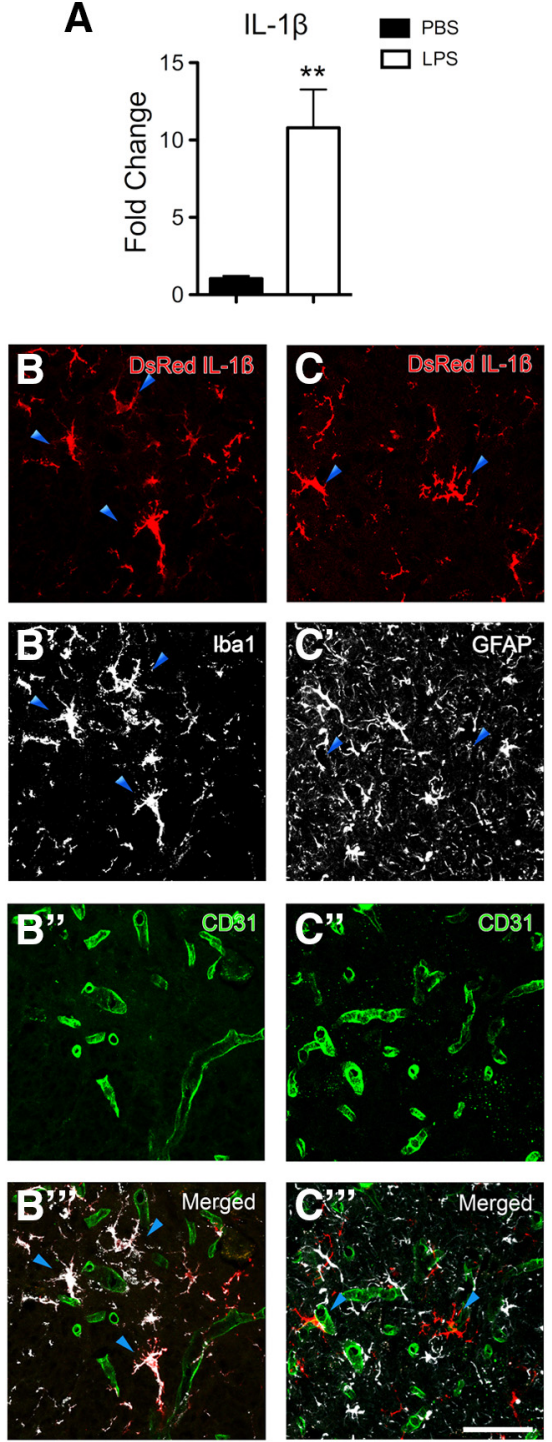

Figure 4. LPSX4 increases the expression of intraspinal IL-1 $\beta$ produced by microglia. $\boldsymbol{A}$, LPSX4 increases intraspinal IL- $1 \beta$ mRNA expression $>10$-fold relative to control (PBSx4) C57BL/6 mouse spinal cord. Data were generated using quantitative real-time PCR analysis of mRNA prepared from whole homogenized spinal cord (containing cervical, thoracic, and lumbar spinal cord segments). $\boldsymbol{B}-\boldsymbol{C}^{\prime \prime \prime}$, Immunofluorescent triple labeling of spinal cord sections from $p l l-1 \beta$-DsRed mice (red; $\boldsymbol{B}, \boldsymbol{C}$. In these mice, the DsRed fluorescent protein gene is expressed under the control of the plL-1 $\beta$. Thus, only cells that can produce IL-1b will express DsRed. Sections stained for Iba $1^{+}$microglia $\left(\boldsymbol{B}^{\prime}, \boldsymbol{B}^{\prime \prime \prime}\right), \mathrm{GFAP}^{+}$astrocytes $\left(\boldsymbol{C}^{\prime}, \boldsymbol{C}^{\prime \prime \prime}\right)$, and $\mathrm{CD}_{31}{ }^{+}$endothelial cells $\left(\boldsymbol{B}^{\prime \prime}{ }^{\prime}, \boldsymbol{C}^{\prime \prime}\right)$ reveal that IL-1 $\beta$ is produced only by microglia. Data are representative of a single experiment (C57BL/6 mice, $n=5 /$ group; $p$ Il- $1 \beta$-DsRed mice, $n=3$ /group); data are the mean \pm SEM. Student's unpaired two-sided test; $* * p<0.01$. Scale bar: $\boldsymbol{C}^{\prime \prime \prime}\left(\right.$ for $\left.\boldsymbol{B}-\boldsymbol{C}^{\prime \prime \prime}\right), 20 \mu \mathrm{m}$.

neuropathology in mice injected with LPSx4. However, during light microscopic analysis of cresyl violet-stained sections, it was obvious that LPSx4 increased the number of satellite cells associated with neurons (Fig. 3B, arrowheads). Immunofluorescent double labeling with neuronal and anti-CD11b antibodies revealed that these cells are microglia that were consistently found adjacent to or physically touching healthy neuronal somata at all spinal levels in LPSx4 mice (Fig. 3I-L). Moreover, double labeling with the microglia-specific antibody P2RY12 and anti-CD11b antibodies confirmed that LPSx4 elicits a reactive microglia reaction without triggering the recruitment of monocyte-derived macrophages (i.e., no $\mathrm{CD} 11 \mathrm{~b}^{+} / \mathrm{P} 2 \mathrm{RY} 12$ - cells were 
Cervical
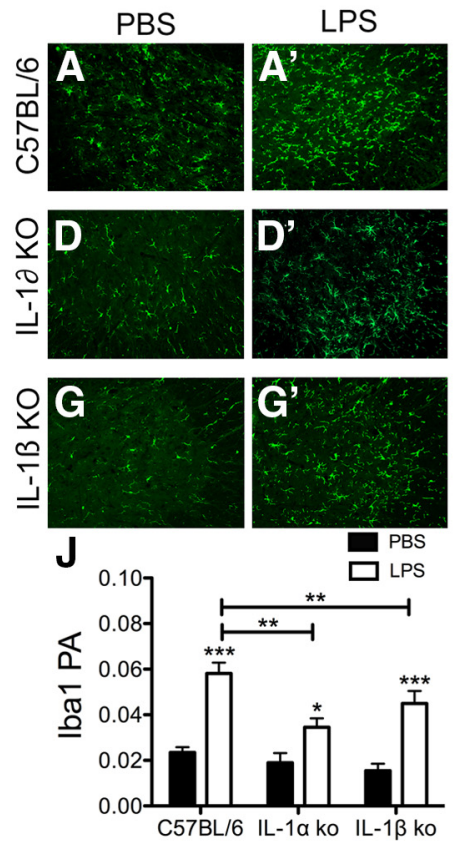

Thoracic
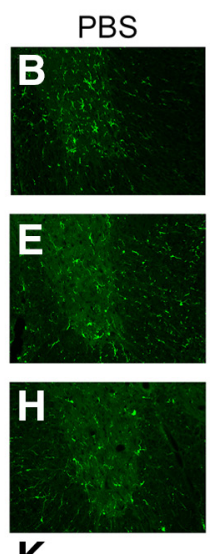

$\mathbf{K}$
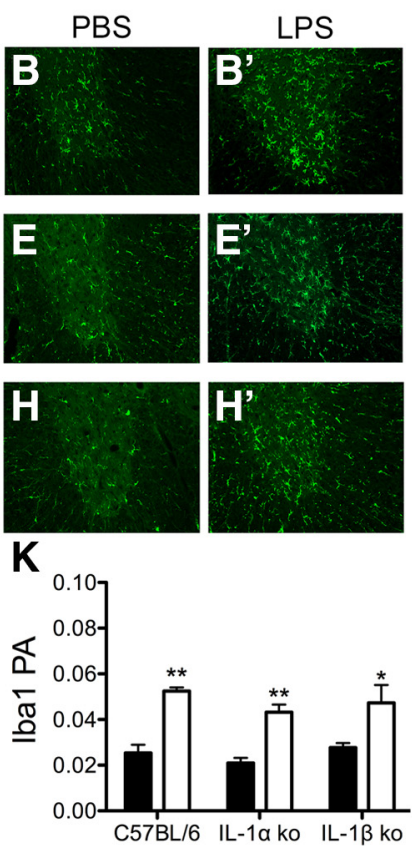

Lumbar
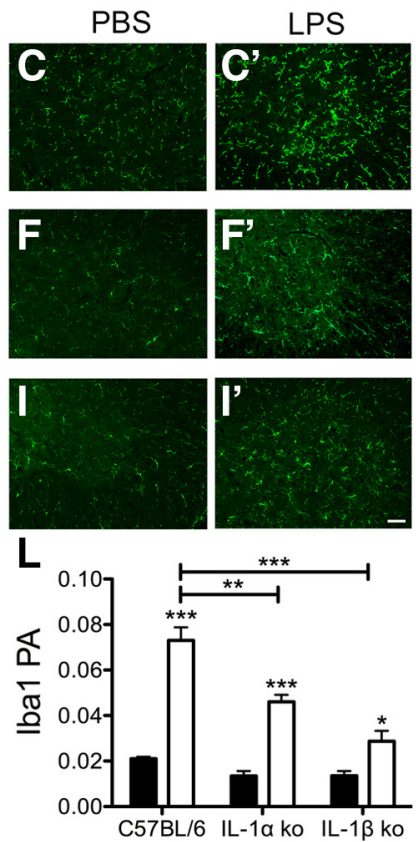

Figure 5. Maximal activation of spinal cord microglia by LPSX4 requires IL-1. A-I and $\boldsymbol{A}^{\prime}-\boldsymbol{I}^{\prime}$, Representative images of cervical $\left(\boldsymbol{A}, \boldsymbol{A}^{\prime}, \boldsymbol{D}, \boldsymbol{D}^{\prime}, \boldsymbol{G}, \boldsymbol{G}^{\prime}\right)$, thoracic $\left(\boldsymbol{B}, \boldsymbol{B}^{\prime}, \boldsymbol{E}, \boldsymbol{E}^{\prime}, \boldsymbol{H}, \boldsymbol{H}^{\prime}\right)$, and lum$\operatorname{bar}\left(\boldsymbol{C}, \boldsymbol{C}^{\prime}, \boldsymbol{F}, \boldsymbol{F}^{\prime}, \boldsymbol{I}, \boldsymbol{I}^{\prime}\right)$ spinal cord ventral horn after PBSx4 $(\boldsymbol{A}-\boldsymbol{I})$ or LPSx4 $\left(\boldsymbol{A}^{\prime}-\boldsymbol{I}^{\prime}\right)$ injections in $\left(57 B \mathrm{~B} / 6\right.$ wild-type mice $\left(\boldsymbol{A}-\boldsymbol{C}\right.$ and $\left.\boldsymbol{A}^{\prime}-\boldsymbol{C}^{\prime}\right)$, IL-1 $\alpha$ knock-out mice $\left(\boldsymbol{D}-\boldsymbol{F}\right.$ and $\left.\boldsymbol{D}^{\prime}-\boldsymbol{F}^{\prime}\right)$, and IL-1 $\beta$ knock-out mice $\left(\mathbf{G}-\boldsymbol{I}\right.$ and $\left.\mathbf{G}^{\prime}-\boldsymbol{I}^{\prime}\right)$. $\boldsymbol{J}-\mathbf{L}$, Quantification of Iba1 PA in the cervical $(\boldsymbol{J})$, thoracic $(\boldsymbol{K})$, or lumbar $(\boldsymbol{L})$ spinal cord reveals that LPSx4 elicits microglial activation in all genotypes, but this response is significantly impaired in IL- $1 \alpha$ and IL- $1 \beta$ KO relative to C57BL/6 mice. J-L, Graphs are representative of a single experiment ( $n=4$ mice/group). One-way ANOVA with Bonferroni's post hoc tests; $J, * p<0.05$ and $* * * p<0.001$, PBS versus LPS within a genotype; $* * p<0.01$, C57BL/6 versus IL- $1 \alpha \mathrm{K} 0$ and C57BL/6 versus IL-1 $\beta$ Ko within LPS treatment; $\boldsymbol{K}, * p<0.05$ and $* * p<0.01$, PBSx4 versus LPSX4 within a genotype; $\boldsymbol{L}, * p<0.05$ and $* * * p<0.001$, PBSX4 versus LPSX4 within a genotype, $* * p<0.01$, C57BL/6 LPSX4 versus IL- $1 \alpha$ Ko LPSX4, and $* * * p<0.001$, C57BL/6 LPSX4 versus IL- $1 \beta$ K0 LPSx4. Scale bar: $I^{\prime}$ (for $A-I^{\prime}$ ), $50 \mu \mathrm{m}$.

observed in the spinal parenchyma; Fig. $3 M-P$ ). Together, these data indicate that LPSx 4 triggers a robust microglia response that is not neurotoxic and does not elicit leukocyte recruitment to the spinal cord.

\section{LPSx 4 causes reactive spinal cord microglia to increase IL-1 $\beta$} expression

We next sought to understand how the LPSx4 model impacts a major gene signature associated with reactive microglia, IL-1 (Liddelow et al., 2017; Liu and Quan, 2018). In the brain, a composite indicator of neuroinflammation is when IL- $1 \beta$ expression increases together with the formation of reactive microglia (Norden et al., 2015; Liu and Quan, 2018; Wendeln et al., 2018). Less is known about spinal cord microglia and IL- $1 \beta$. In our hands, a single LPS injection fails to elicit morphologic transformation of spinal cord microglia (Fig. 2A), and in rats, a single systemic injection of LPS failed to increase intraspinal IL- $1 \beta$ mRNA (Huxtable et al., 2013). However, LPSx4 consistently elicits reactive microglia throughout the spinal cord, and this is accompanied by a $>10$-fold increase in intraspinal IL- $1 \beta$ mRNA expression (LPSx 4 vs PBSx 4 mice, $p<0.01$, Fig. $4 A$ ).

DsRed-IL- $1 \beta$ reporter mice were used to determine which spinal cord cell types produce IL- $1 \beta$ in response to LPSx 4 . In these mice, IL- $1 \beta$-producing cells increase expression of DsRed (Matsushima et al., 2010; Bastien et al., 2015). LPSx4 increased DsRed expression only in Iba ${ }^{+}$cells (Fig. $4 B, B^{\prime}, B^{\prime \prime \prime}$ ). Thus, in spinal cord, LPSx4 elicits nonpathologic neuroinflammation with reactive IL- $1 \beta^{+}$microglia evenly distributed throughout the spinal parenchyma.
Reactive intraspinal microgliosis after LPSx4 requires IL-1dependent microglia-endothelia cross talk

To determine whether the LPS-dependent increase in microglial IL-1 is a downstream consequence of spinal microglia activation or is required to promote the reactive microglia response, the ability to elicit reactive microglia with LPSx4 was measured in IL- $1 \beta$ and IL- $1 \alpha$ knock-out mice. When compared with PBSinjected genotype controls, LPSx 4 consistently elicits reactive microglia, regardless of the presence of IL- $1 \beta$ or IL- $1 \alpha$ (Fig. 5). However, relative to WT mice, the magnitude of morphologic transformation of spinal cord microglia was significantly reduced in the cervical and lumbar spinal cord in both IL- $1 \beta$ and IL- $1 \alpha$ knock-out mice (Fig. 5). These data, together with those in Figure 4, indicate that an optimal reactive microglia response requires IL-1.

Since LPS does not cross the BSCB, we sought to determine how LPSx 4 and subsequent IL-1 production elicit reactive intraspinal microglia. Endothelial cells that line intraspinal microvessels are the only other CNS-resident cell type to express the LPS receptor TLR4 at levels comparable to microglia (Zhang et al., 2014b). Since endothelial cells are at the interface between microglia and circulating LPS, we hypothesized that LPSx4 triggers IL-1-dependent cross talk between spinal cord microglia and endothelial cells. First, we analyzed microglia-endothelia interactions via microscopy. In naive or PBS-injected mice, spinal cord microglia, at all spinal levels, tile homogeneously throughout gray matter and white matter (Fig. 6A,C,F,I). In contrast, in LPSx4-injected mice, reactive microglia frequently cluster around or adjacent to the central canal and blood vessels (Fig. $6 B, D, G, J)$. This repositioning of microglia alongside endothelia was most obvious within the gray matter of the cervical and 

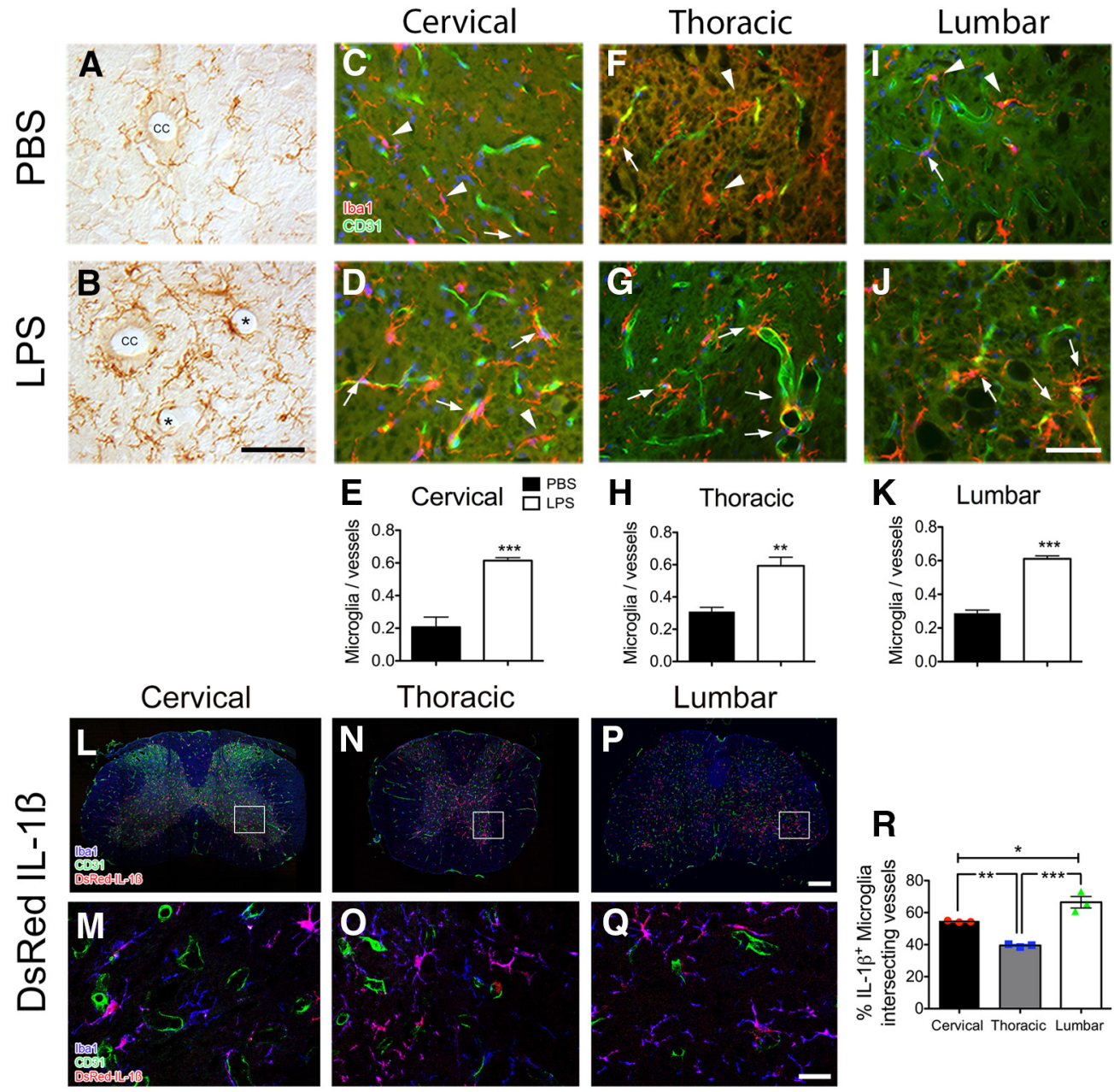

Figure 6. LPSX4 increases the number of reactive IL-1 $\beta^{+}$perivascular microglia. $A, B$, lba1 immunoperoxidase staining in the lumbar spinal cord in mice injected with PBSx4 (A) or LPSX4 (B) show enhanced clustering of microglia around/adjacent to microvascular profiles (asterisks) and to central canal (cc). $\boldsymbol{C}-\boldsymbol{K}$, Representative images $(\boldsymbol{C}, \boldsymbol{D}, \boldsymbol{F}, \boldsymbol{G}, \boldsymbol{I}, \boldsymbol{J})$ and quantification $(\boldsymbol{E}, \boldsymbol{H}$, $\boldsymbol{K})$ of microglia (Iba1; red) intersecting with or adjacent to spinal cord endothelia (CD31; green). LPSX4 increases the number of microglia-endothelia interactions at all spinal levels. $\boldsymbol{L}-\boldsymbol{R}$, Representative images $(\boldsymbol{L}-\mathbf{Q})$ and image quantification $(\boldsymbol{R})$ reveal that most $(\sim 40-70 \%)$ microglia that intersect with blood vessel profiles are IL-1 $\beta^{+}$(DsRed). Graphs are representative of a single experiment; data are mean \pm SEM; Student's unpaired two-sided $t$ tests $(\boldsymbol{E}, \boldsymbol{H}, \boldsymbol{K}$, using $\mathrm{C57BL} / 6$ mice; $n=4 /$ group $)$ and one-way ANOVA with Bonferroni's multiple-comparison post hoc tests ( $\boldsymbol{R}$, using pll-1 $\beta$-DsRed mice; $n=3$ /group); *p $<0.05 ; * * p<0.01 ; * * * p<0.001$. Scale bars: $\boldsymbol{B}$ (for $\boldsymbol{A}, \boldsymbol{B}$ ), $50 \mu \mathrm{m} ; \boldsymbol{J}$ (for $\boldsymbol{C}, \boldsymbol{D}, \boldsymbol{F}, \boldsymbol{G}, \boldsymbol{I}, \boldsymbol{J}), 20 \mu \mathrm{m} ; \boldsymbol{P}$ (for $\boldsymbol{L}-\boldsymbol{P}$ ), $200 \mu \mathrm{m} ; \boldsymbol{Q}$ (for $\boldsymbol{M}$ Q), $20 \mu \mathrm{m}$.

lumbar enlargements, where blood vessel density and vascular perfusion are highest (Fig. 6C-J; Mautes et al., 2000). Overall, LPSx4 increased microglia-endothelia interactions approximately threefold at all spinal levels (Fig. 6E,H,K).

To determine whether reactive perivascular microglia were also IL- $1 \beta^{+}$, DsRed IL-1 $\beta$ reporter mice were injected with LPSx4. Depending on spinal level, most $(\sim 40-70 \%)$ reactive IL$1 \beta^{+}$microglia intersected with blood vessel profiles, with the largest numbers found along $\mathrm{CD} 31^{+}$vascular profiles in the cervical and lumbar spinal cord (Fig. $6 L-R$ ). These data suggest that in response to LPSx4, reactive microglia increase the expression of IL- $1 \beta$ and position themselves to receive cues from endothelial cells.

Next, we sought to establish the mechanism by which LPS $\mathrm{x} 4$ triggers intercellular cross talk between endothelial cells and microglia. Endothelia express $>10$-fold more IL-1R1 than other glia and neurons (Zhang et al., 2014b) and can induce the upregulation of IL-1 in microglia (Liu et al., 2019). Therefore, the enhanced production of IL-1 by microglia after LPSx4 (Figs. 4, 5) could be driven by paracrine signals from IL- $1 \mathrm{R}^{+}$endothelial cells. To assess whether LPSx4 increases IL-1R expression in spinal cord endothelia, we used $I l 1 r 1^{\mathrm{GR} / \mathrm{GR}}$ mice. In this IL-1R1 reporter mouse line, IL-1R1 mRNA-expressing cells can be tracked because of a knock-in TdTomato reporter gene that is coexpressed with IL-1R1 (Liu et al., 2019). Similar to the progressive morphologic changes observed in microglia after repeat LPS injections, the relative area of spinal cord occupied by IL-1R $1^{+}$blood vessel profiles doubled after three and four daily injections of LPS, relative to 1 or $2 \mathrm{~d}$ of LPS injections (Fig. $7 A-F$ ). Again, four serial LPS injections were required to trigger the perivascular reactive microglia response (Fig. $7 G, H$ ). These data indicate that in response to (four) serial LPS injections, microglia undergo progressive morphologic transformation (Fig. $2 A-D, F$ ), proliferate (Fig. 2E,G,H), migrate to blood vessels (Fig. 6A-K), and increase the expression of IL-1 (Fig. 4) as a result of IL-1R-dependent endothelia-microglia cross talk.

To better understand the hierarchy in this IL-1R1-dependent signaling network and its relationship to the development of nonpathologic neuroinflammation, we applied the LPSx4 protocol in a novel $I l 1 r 1^{\mathrm{r} / \mathrm{r}}$ mouse line. These mice are equivalent to Illr $r^{r / r}$-null mice because normal IL-1R1 expression is blocked 

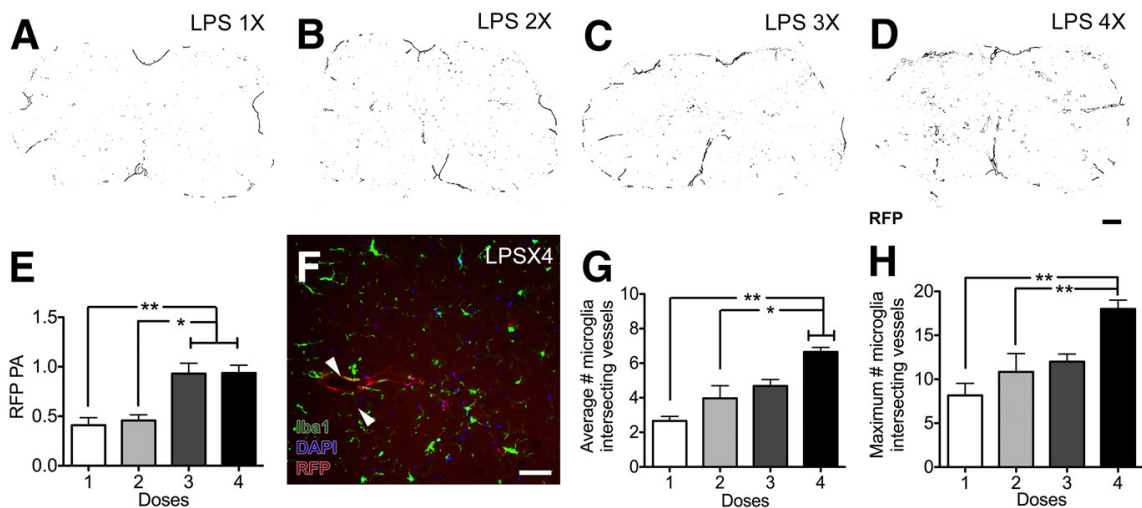

Figure 7. LPSX4 increases vascular IL-1R1 mRNA expression. $\boldsymbol{A}-\boldsymbol{E}$, Representative images of spinal cord cross sections (A$D$ ) from IL-1R1 reporter mice $\left(\| / 1 r 7^{G R / G R}\right)$ reveal that three to four successive daily injections of LPS activate a robust IL-1R1 ${ }^{+}$ vascular network (quantified in $E$ ). Images of endogenous TdTomato reporter (IL-1R1) are binarized for clear visualization of vascular profiles. $\boldsymbol{F}$, Triple labeling for microglia (Iba1; green), IL-1R1 mRNA (red), and DAPI (blue) shows that numerous microglia are associated with IL-1R1 ${ }^{+}$vascular profiles in the lumbar spinal cord after LPSX4. $\boldsymbol{G}, \boldsymbol{H}$, The average (G) and maximum $(\boldsymbol{H})$ number of microglia that abut IL1R1 ${ }^{+}$blood vessels increased only after four daily injections of LPS. Graphs are representative of a single experiment; data are the mean \pm SEM. One-way ANOVA with Bonferroni's post hoc tests (II1r ${ }^{\mathrm{GR}}$ ${ }^{G R}$ mice, $n=3 /$ group); $* p<0.05 ; * * p<0.01$. Scale bars: $\boldsymbol{D}$ (for $\boldsymbol{A}-\boldsymbol{D}$ ), $100 \mu \mathrm{m} ; \boldsymbol{F}, 50 \mu \mathrm{m}$.

by intronic insertion of a loxP flanked disruption sequence. However, when these mice are crossed with cell type-specific Cre promoter mouse lines, excision of the disruption sequence in offspring restores IL-1R1 expression only in cells with the specific promoter (Liu et al., 2019). To selectively restore IL-1R1 expression in endothelia or microglia, which also express IL-1R1 (Bruttger et al., 2015), Illr ${ }^{\mathrm{r} / \mathrm{r}}$ mice were crossed with Tie2-Cre or Cx3cr1-Cre mice. In the resulting Tie2-Cre-Illr1 ${ }^{r / r}$ or $\mathrm{Cx}_{3} \mathrm{Cr} 1$ $\mathrm{Cre}_{\mathrm{Ill}} \mathrm{rl}^{r / r}$ offspring, IL-1R1 is selectively restored (r) in endothelia or microglia, respectively. Although LPSx4 consistently elicits reactive microglia in wild-type control (C57BL/6) mice (Fig. $8 A, B, I$ ), it did not do so in $I l 1 r 1^{\mathrm{r} / \mathrm{r}}$ mice (Fig. 8C,D,I). Instead, in these mice, spinal cord microglia resembled the resting microglia found in wild-type mice injected with PBS (Fig. 8, compare $A, C$; Fig. 8I, compare LPSx4, PBSx4). Reactive microgliosis is again elicited by LPSx 4 after IL-1R1 expression is selectively restored in microglia $\left(\mathrm{C} \times 3 \mathrm{crl}-\mathrm{Cre}-\mathrm{Ill} 1 \mathrm{rl}{ }^{r / r}\right)$ or endothelia (Tie2-Cre-Illr $r^{r / r}$ mice; Figs. $8 E-H$ ). These effects were consistent at all spinal levels, although data presented here were from lumbar spinal cord where the most consistent and robust effects of LPSx4 occurred (Figs. 1, 5, 6).

Noted increases (or decreases) in reactive microgliosis, as defined by two-dimensional proportional area measurements, which can be affected by cell proliferation and cell migration, were also confirmed by quantifying corresponding changes in cell volume. Three-dimensional analysis of reactive microglia profiles, including cell bodies and microglia processes, revealed that LPSx 4 consistently increased microglial cell volume, and this effect was abolished in the absence of IL-1-dependent signaling in microglia or endothelia (Fig. 8J-S). Together, these data suggest that serial injections of systemic LPS elicit a bidirectional IL-1-dependent signaling network that amplifies cross talk between spinal cord endothelia and reactive microglia. We next tested the functional significance of this novel neuroinflammatory reaction in the spinal cord.

\section{LPS 4 confers neuroprotection and prevents paralysis after ISCI}

Systemic injections of LPS before an ischemic or traumatic insult can protect the brain (Rosenzweig et al., 2004; Chen et al., 2012;
Wendeln et al., 2018). The mechanisms underlying the neuroprotective effects of LPS "preconditioning" are incompletely understood but involve reprogramming of microglia function (Marsh et al., 2009a,b; Stevens et al., 2011; Chen and Trapp, 2016). Although preconditioning may not be practical as a treatment for naturally occurring traumatic CNS injuries or cerebral vascular accidents, it could benefit individuals who plan elective surgery to repair aortic aneurysms (Gravereaux et al., 2001). In these individuals, there is currently no way to prevent the devastating perioperative complication of spinal cord ischemia with paralysis (Awad et al., 2010). Previously, we showed that, like in humans, aortic cross clamp in adult C57BL/6 mice reduces blood flow to the thoracic and lumbar spinal cord, causing reproducible ISCI across these spinal segments, particularly in spinal cord gray matter (Awad et al., 2010), while preserving the cervical spinal cord. Data in Figure 9 illustrate pathologic features of this model. Specifically, after aortic cross clamp with reperfusion (see Materials and Methods), the cervical spinal cord was unaffected; there was no overt neuron loss, evidence of neuroinflammation, or obvious extravascular leak of fibrinogen, an immunohistochemical marker of increased blood-spinal cord barrier permeability (Fig. 9B,C). However, throughout the ischemic thoracic and lumbar gray matter, marked neuronal loss occurred and was associated with a robust innate immune response and a significant increase in extravascular fibrinogen accumulation (Fig. 9D-G,H).

Identical pathology occurs in mice injected with PBSx4 (Fig. 9, compare $A, I$, and $A, F)$. Obvious ischemia-induced damage to the spinal microvasculature was evident in these mice (Fig. 9A). By $48 \mathrm{~h}$ postreperfusion, this pathology was accompanied by nearly complete hindlimb paralysis in most $(n=7 / 8)$ PBSx4 mice (Fig. $9 M, N$ ). These mice did not show signs of spontaneous recovery even $7 \mathrm{~d}$ after ISCI. Conversely, in mice receiving four daily injections of LPS before ISCI (i.e., LPSx4), there was no gross evidence of damage to the spinal vasculature (Fig. 9A), obvious intraspinal inflammation (Fig. 9J), or fibrinogen accumulation; the latter was restricted to the lumen of the microvasculature throughout the spinal cord (Fig. 9K,L, lumbar spinal cord). LPSx4 also protected ventral horn motor neurons from ischemic damage. Specifically, greater numbers of large $\mathrm{NeuN}^{+}$ motor neurons were found throughout the ventral horn in LPSx 4 mice (Fig. 9O,P). Although the ability of LPSx4 to protect the spinal cord from ischemic injury was consistent, it was not absolute. Adjacent sections stained with Gallyas silver stain (Fig. 9Q,R) or anti-LC3 antibodies (Fig. 9S,T) revealed that some neurons were degenerating or undergoing autophagy and that a subset of mice ( $n=3$ of 8$)$ developed mild hindlimb deficits, characterized by loss of forelimb-hindlimb coordination during overground locomotion with paw rotation during stepping (Fig. $9 M, N)$. Together, these data indicate that LPSx4 markedly reduces the pathologic consequences of ISCI.

\section{Microglia enhance the neuroprotective effects of LPS 4}

To determine whether the neuroprotective effects of LPSx4 require microglia, a loss-of-function experiment was performed. Microglia were depleted by feeding mice for $14 \mathrm{~d}$ with a chow 

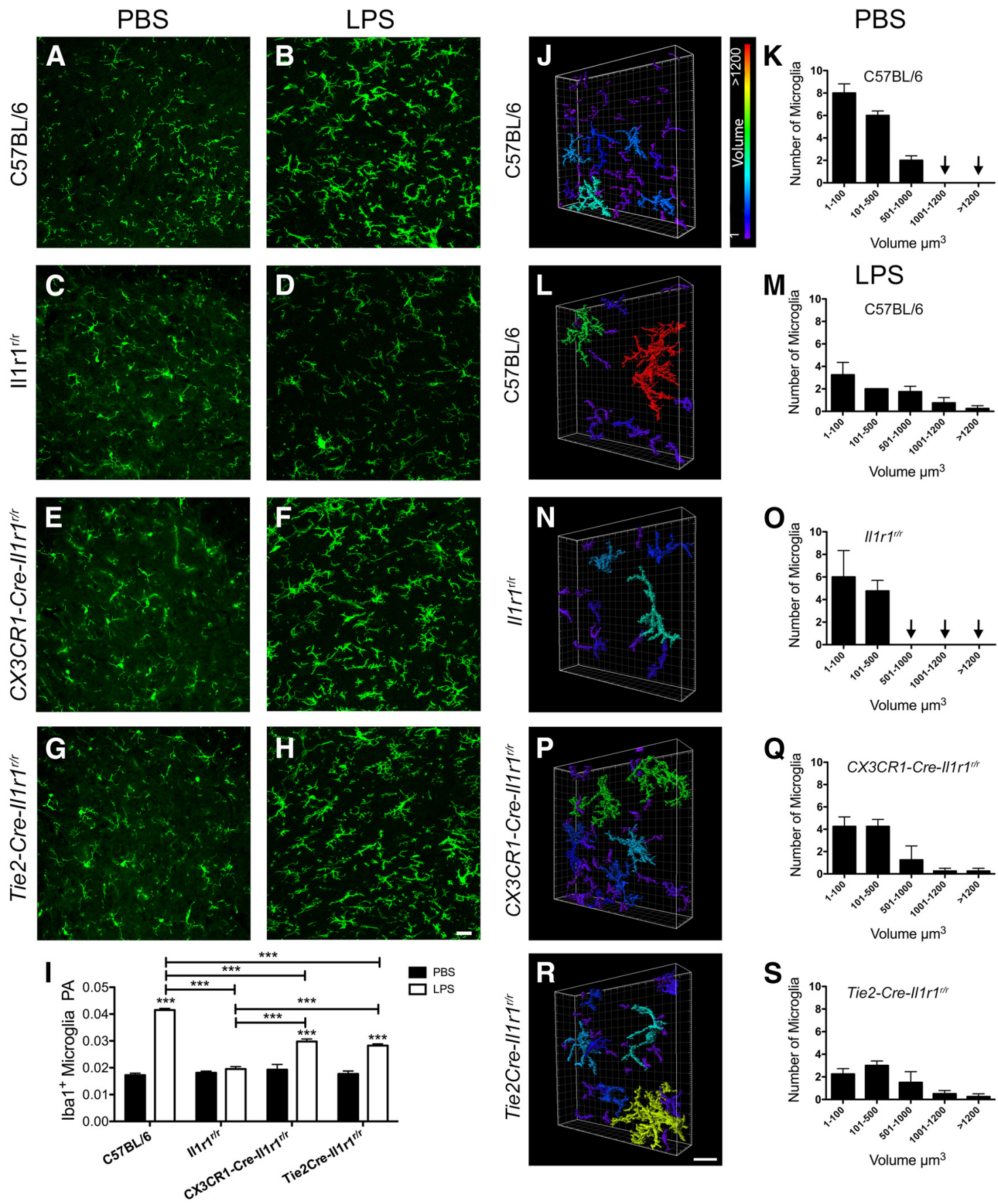

$\mathbf{S}$

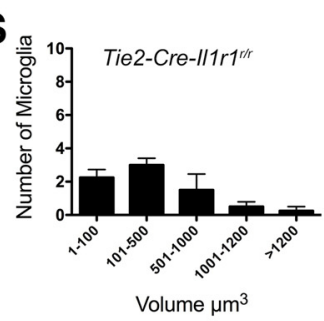

Figure 8. Optimal activation of spinal cord microglia by LPSX4 requires IL-1-dependent microglia-endothelia cross talk. $\boldsymbol{A}-\boldsymbol{B}$, Relative to PBS X4 (A), LPSX4 (B) elicits a consistent reactive microglia response throughout the spinal cord of C57BL/6 mice. In II1rr ${ }^{\mathrm{r} / \mathrm{P}} \mathrm{PBS} \times 4$ mice (C), microglia exhibit a resting morphology, similar to PBSx4 in C57BL/6 mice (compare $\boldsymbol{A}$, C). D, LPSx4 cannot elicit a reactive microglia phenotype when injected into mice with global IL-1R1 deficiency (IIIr ${ }^{T / r}$ mice). $\boldsymbol{F}, \boldsymbol{H}$, The ability of LPSx4 to elicit reactive microglia returns when the expres-

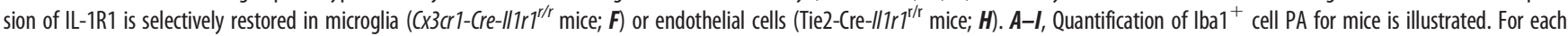
experimental group, LPSx4 was compared with PBSx4, and all transgenic mice used their respective littermate controls for PBSx4 comparisons. $\boldsymbol{J}-\boldsymbol{S}$, Representative $3 D$ images $(\boldsymbol{J}, \mathbf{L}, \boldsymbol{N}, \boldsymbol{P}, \boldsymbol{R})$ and quantification $(\boldsymbol{K}, \boldsymbol{M}, \mathbf{O}, \mathbf{Q}, \mathbf{S})$ of microglia volume in sections from $C 57 \mathrm{BL} / 6$ mice and genetically modified mouse genotypes after $L P S \times 4(\boldsymbol{L}, \boldsymbol{N}, \boldsymbol{P}, \boldsymbol{R})$. Note that after $L P S \times 4$, the number of microglia with cell volumes $>1000 \mu \mathrm{m}^{3}$ increases relative to PBS (compare $\boldsymbol{K}, \boldsymbol{M}$ ). $\mathbf{O}-\mathbf{S}$, These 3D morphologic changes caused by LPSX4 are abolished in IL-1RT ${ }^{\mathrm{r} / \mathrm{r}}$ mice $(\boldsymbol{O})$ but return after selective restoration of IL-1R1 in microglia $(\boldsymbol{P}, \mathbf{Q})$ or endothelial cells $(\boldsymbol{R}, \boldsymbol{S})$. All images and data were analyzed using sections from lumbar spinal cord, and for the 3D images the number of microglial cells analyzed was within a field view area of $1.5 \mathrm{~mm}^{2}$. Black arrows reveal the absence of microglia at the indicated volumes. Data were generated from a single experiment with $n=4$ mice/group. Data are the mean \pm SEM and were analyzed via one-way ANOVA with Bonferroni's post hoc tests; $* * * p<0.001$. Scale bars: $\boldsymbol{H}$ (for $\boldsymbol{A}-\boldsymbol{H}), 10 \mu \mathrm{m} ; \boldsymbol{R}$ (for $\boldsymbol{J}, \boldsymbol{L}, \boldsymbol{N}, \boldsymbol{P}, \boldsymbol{R}$ ), $10 \mu \mathrm{m}$.

laced with PLX (Elmore et al., 2014; Dagher et al., 2015; Spangenberg et al., 2016). Mice fed vehicle diet served as controls. Half the mice in each group were injected with LPSx4 or PBSx4 after which the anatomic and functional consequences of ISCI were compared. In vehicle + PBSx4 control mice, intraspinal pathology and paralysis developed as expected, mirroring the effects of ISCI seen in control mice in Figures 9 and 10, $A$ and $E$. Also, LPSx4 again protected mice from ISCI if they were fed vehicle chow (Fig. 10B,F). Depleting microglia did not affect the natural course of ISCI in mice injected with PBS (PLX+PBSx4; 

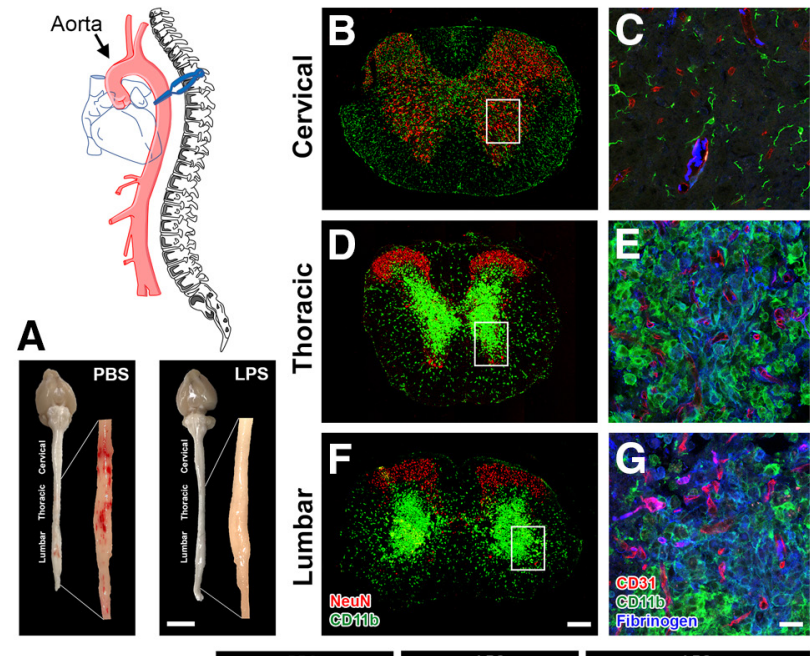

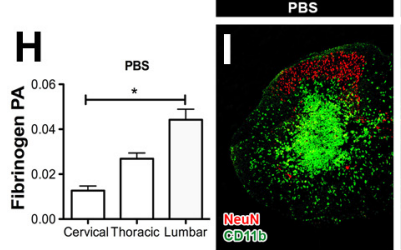

$\mathbf{M}$
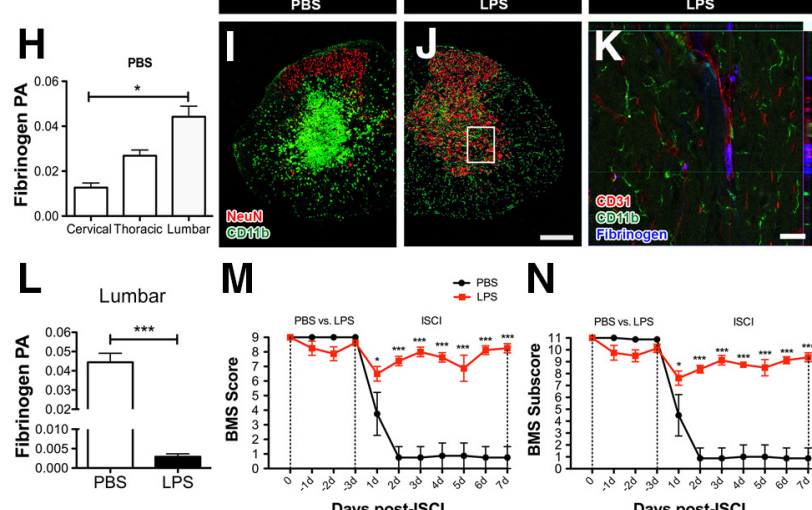

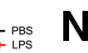
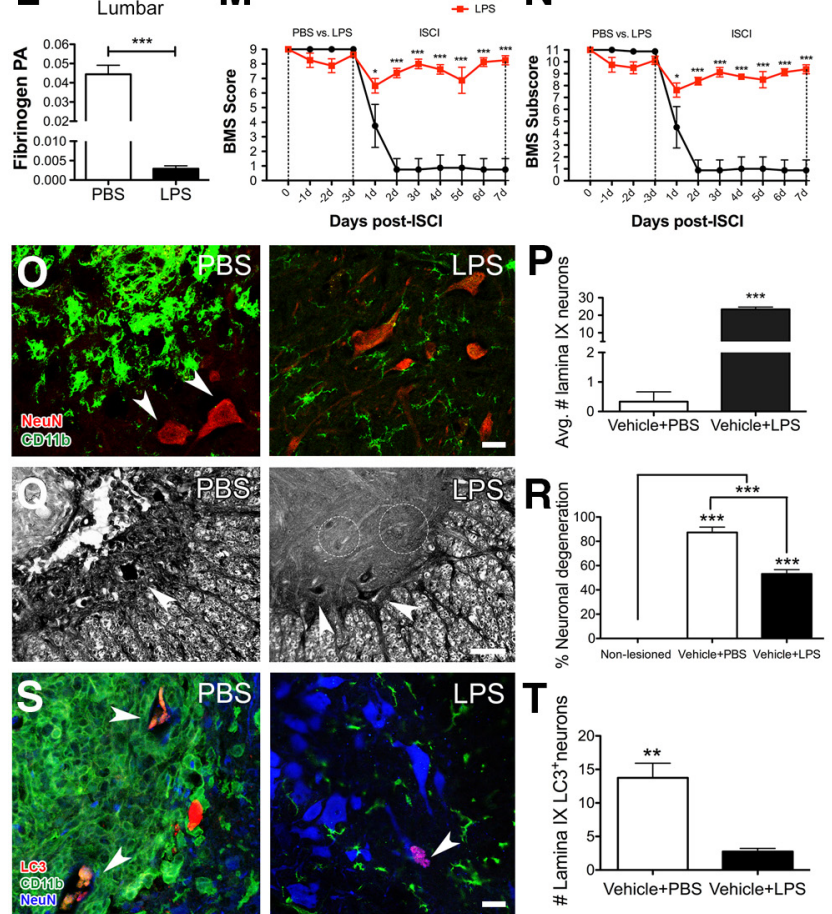

Figure 9. LPSX4 is neuroprotective and prevents hindlimb paralysis after ISCl. Schematic of the ISCI model: aneurysm clips are placed on the descending aorta of mice, reducing blood flow to the thoracic and lumbar spinal cord. $A$, Spinal cord specimens freshly isolated from PBSX4- and LPSX4-treated mice show that ISCI causes obvious vascular injury in spinal cords of PBSx4 mice, but not in spinal cords from LPSx4 mice. $\boldsymbol{B}, \boldsymbol{D}, \boldsymbol{F}$, Immunofluorescent double staining for microglia/macrophages (CD11b; green) and neurons (NeuN; red) show that ISCI causes consistent intraspinal inflammation and neuron loss in the thoracic $(\boldsymbol{D})$ and lumbar (F) spinal cord, but not in the cervical $(\boldsymbol{B})$ spinal cord in C57BL/6 wild-type mice. $\boldsymbol{C}, \boldsymbol{E}, \boldsymbol{G}$, Immunofluorescence triple staining for microglia/macrophages (CD11b; green), endothelial cells (CD31; red), and fibrinogen (blue), a circulating protein and biomarker of vascular permeability, shows that there is no increase in blood-spinal cord barrier permeability in the cervical spinal cord after ISCl; fibrinogen labeling is restricted to the vascular lumen (C); conversely, plasma proteins leak into the spinal parenchyma at thoracic $(\boldsymbol{E})$ and lumbar $(\boldsymbol{G})$ spinal levels. $\boldsymbol{H}$, The magnitude of intraspinal fibrinogen accumulation by spinal levels is
Fig. $10 C, G$ ); spinal cord pathology in this group was similar to the effects of ISCI in C57BL/6 mice (Fig. 9) or vehicle+PBSx4 groups, with the exception that the relative magnitude of the myeloid cell response in the ischemic gray matter was reduced, presumably because without microglia only nonmicroglial-derived macrophages occupied the degenerating gray matter (Fig. 10, compare $C, G$ and $A, E$ ). Depleting microglia did, however, significantly reduce the neuroprotective effects of LPSx4. Notably, in PLX+LPSx 4 mice, significant neuronal loss was evident in the ventral spinal cord gray matter, coincident with an increase in the accumulation of dense foci of $\mathrm{CD} 11 \mathrm{~b}^{+} \mathrm{P} 2 \mathrm{RY} 12^{-}$monocytederived macrophages (Fig. 10D,H,I). Also, without microglia, LPSx4-treated mice developed consistent motor deficits during open-field analysis (Fig. 10K). Nonsubjective quantitative TreadScan and beam-walking assays, which assess fine motor skills including coordination and postural balance, confirmed that microglia were required for LPSx4 to confer optimal preservation of neurologic function (Fig. $10 K-M$ ).

To confirm the relative efficiency of microglia depletion, tissue sections were stained with the P2RY12 antibody that labels a purinergic receptor expressed in the CNS only on microglia (Butovsky et al., 2014). P2RY12 ${ }^{+}$microglia, which are distributed throughout lesioned and intact spinal cord in vehicle+PBS group (Fig. 10E), were absent in PLX+PBS mice (Fig. 10G), indicating that PLX-mediated microglia depletion was efficient.

\section{IL-1-dependent microglia-endothelia cross talk is necessary to achieve optimal LPSx4-mediated neuroprotection after ISCI}

Data above suggest that the ability of LPSx4 to elicit reactive microglia and confer optimal neuroprotection requires bidirectional IL-1-dependent signaling between spinal cord endothelia and microglia. To prove this, we again used mouse genetics to probe IL-1R1 signaling in this context. Specifically, IL-1-dependent signaling was inhibited via conditional deletion of IL-1R1 in either microglia or endothelia using Cx3cr1-Cre-Il1r1 $1^{f / f}$ or Tie2Cre-Il1r $f^{f / f}$ mice, respectively. Mice in each group were injected with LPSx4 then each received ISCI. Wild-type C57BL/6 mice also received LPSx4, and ISCI and served as controls. Consistent with data in Figure 8, the reactive microglia response that

quantified. I, In control (PBSX4) mice, ISCI causes intraspinal pathology and neuroinflammation that is identical to that in C57BL/6 ISCI mice (compare $\boldsymbol{F}, \boldsymbol{I}) . \boldsymbol{A}, J-L$, LPSX4 prevents this ISCl-induced pathology $(\boldsymbol{l})$ and reduces BSCB permeability $(\boldsymbol{A}, \boldsymbol{K}, \boldsymbol{L})$; note that fibrinogen labeling was restricted to the lumen of the spinal cord microvasculature $(K)$. $M, N$, BMS open-field locomotor analyses $(\boldsymbol{M})$ and BMS subscores $(\boldsymbol{M})$ reveal consistent and severe hindlimb paresis/paralysis 24-48 h post-ISCI in control (PBSX4) mice. Conversely, only a subset ( $n=3$ of 8 ) of LPSX4-treated mice develop mild neurologic impairment. $\mathbf{O}, \boldsymbol{P}$, While most ventral horn motor neurons were lost in control mice, many NeuN ${ }^{+}$motor neurons survive throughout the ventral horn in LPS4 mice. $\mathbf{Q}, \boldsymbol{R}$, Silver staining shows that ISCI causes neuron degeneration ( $\boldsymbol{Q}$, white arrowheads) in both PBSx4 and LPS4 mice but that significantly less neurodegeneration occurs in LPSX4 mice ( $Q, \boldsymbol{R}$; dashed circles, healthy neurons). $\boldsymbol{S}, \boldsymbol{T}$, Staining for autophagic neurons ( $\mathrm{LC}^{+}$red) reveals that ISCl increases autophagy in both groups ( $\mathbf{S}$, white arrowheads), indicating a potential increase in autophagy-induced cell death, but, again, the number of autophagic neurons is significantly reduced by LPS $\times 4(S, T)$. Fibrinogen labeling (mean \pm SEM) was analyzed using a one-way ANOVA $(\boldsymbol{H})$ and $t$ test $(\boldsymbol{L})$ with Bonferroni's post hoc tests (PBSx4 vs LPSX4, $n=4$ mice/group). Behavioral data $(\boldsymbol{M}, \boldsymbol{M})$ are the mean \pm SEM and were generated from a single experiment and analyzed using two-way ANOVA with Bonferroni's post hoc tests (PBSx4 vs LPSX4, $n=8$ mice/group). $\boldsymbol{P}, \boldsymbol{T}$ : Student's unpaired two-sided $t$ tests $(\boldsymbol{P}, n=3$ mice/group; $\boldsymbol{T}, n=4$ mice/group); $\boldsymbol{R}$ : one-way ANOVA, ( $n=4$ mice/group). $* p<0.05, * * p<0.01$, and $* * * p<0.001$. Scale bars: $\boldsymbol{A}$ : gross images of entire CNS, $0.5 \mathrm{~cm}$; enlarged segment of spinal cord, $1.2 \mathrm{~cm} ; \boldsymbol{F}$ (for $\boldsymbol{B}, \boldsymbol{D}$, F), $200 \mu \mathrm{m} ; \boldsymbol{G}$ (for $\mathbf{C}, \boldsymbol{E}, \mathbf{G}), 20 \mu \mathrm{m} ; \boldsymbol{J}$ (for $\boldsymbol{I}, \boldsymbol{J}), 200 \mu \mathrm{m} ; \boldsymbol{K}, \mathbf{O}, \mathbf{S}, 20 \mu \mathrm{m} ; \mathbf{Q}, 50 \mu \mathrm{m}$. 


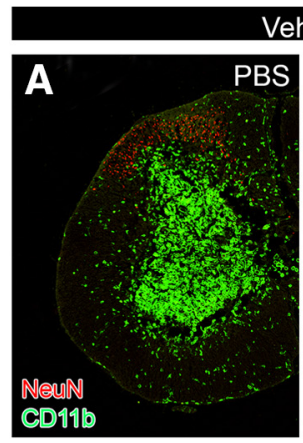

\section{Vehicle}
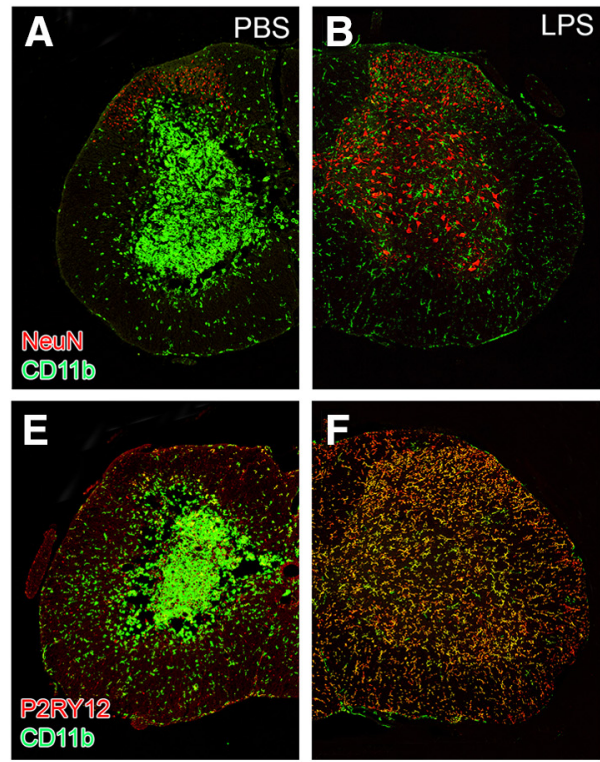

I
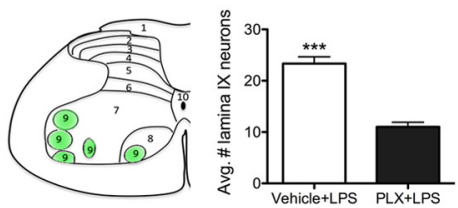

Plexxikon 5622
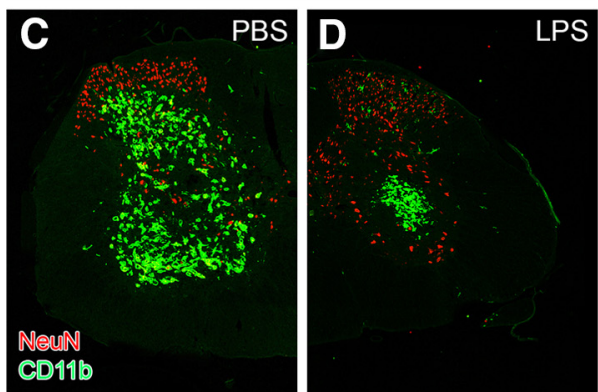

G
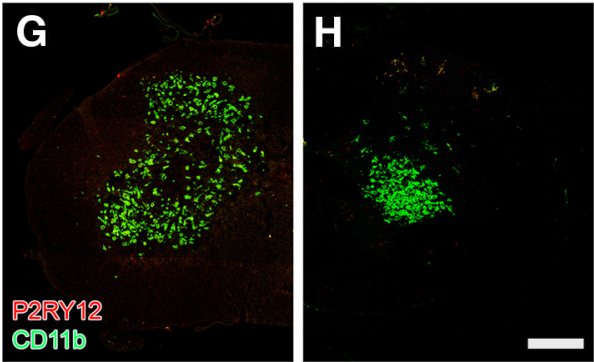

$\mathbf{J}$

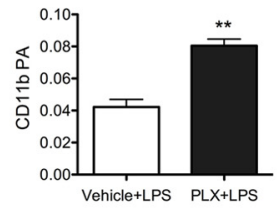

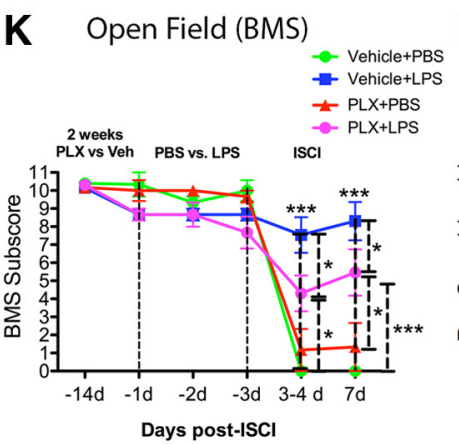
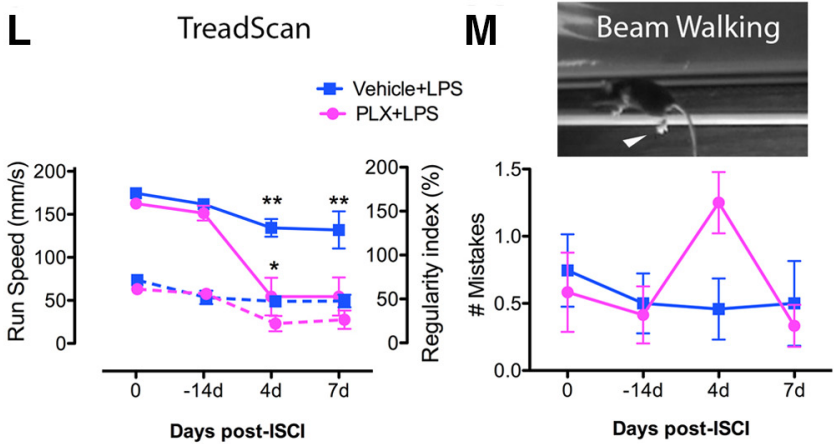

Figure 10. Microglia are required for optimal neuroprotection by LPSX4. $\mathbf{A}-\boldsymbol{H}$, Representative lumbar spinal cord cross sections after ISCI in PBSx4- or LPSx4-treated mice fed either vehicle chow $(\boldsymbol{A}, \boldsymbol{B}, \boldsymbol{E}, \boldsymbol{F})$ or chow laced with the microglia-depleting CSF1R antagonist PLX $(\boldsymbol{C}, \boldsymbol{D}, \boldsymbol{G}, \boldsymbol{H})$. ISCl causes neuron loss and a florid intraspinal inflammatory response in PBSx4 control mice (compare Fig. 9). In PBSX4 mice, depleting microglia with PLX chow does not affect the pathology caused by ISCI (compare $\boldsymbol{A}$, $\boldsymbol{C}$. Conversely, the marked neuroprotection from ISCI conferred by LPSX4 (B) is lost after pharmacological depletion of microglia $(\boldsymbol{D})$. $\boldsymbol{E}-\boldsymbol{H}$, Staining for the microglia-specific marker P2RY12, which is prevalent in vehicle-fed mice $(\boldsymbol{E}$, $\boldsymbol{F})$ confirms depletion of microglia in mice fed PLX $(\boldsymbol{G}, \boldsymbol{H})$. In PLX-fed mice, monocyte-derived $\mathrm{CD}_{11 \mathrm{~b}^{+}}$macrophages infiltrate regions previously occupied by intact spinal cord gray matter. In $\boldsymbol{H}$, note that without microglia, monocyte-derived macrophages preferentially infiltrate the ventral horn, which is now devoid of surviving motor neurons (compare $\boldsymbol{B}, \boldsymbol{F}$ with $\boldsymbol{D}, \boldsymbol{H}$ ). $\boldsymbol{I}, \boldsymbol{J}$, Average number of surviving neurons in LPSX4-treated mice is significantly decreased if microglia are depleted before LPSX4 treatment $(\boldsymbol{I})$ and is associated with a compensatory increase in presumptive $\mathrm{CD}_{11 b^{+}}$monocytederived macrophages in laminae IX (J). $\boldsymbol{K}, I S C I$ causes complete hindlimb paralysis after 3-4 d in control mice (vehicle+PBS and PLX + PBS), while LPSX4 (vehicle + LPS) significantly protects mice from ischemia-induced neurologic impairment. This protection is significantly diminished without microglia (PLX+LPS). L, Nonsubjective quantitative analysis with TreadScan reveals that without microglia, LPSX4 cannot preserve fine details of locomotor function; both run speed (solid lines) and regularity index (dashed lines) are reduced in PLX+LPS mice compared with vehicle+LPS mice. $M$, Similarly, beam walk analysis reveals that without microglia (PLX+LPS), ISCI causes transient deficits in coordination and balance. $K, L$, Graphs are representative of two independent experiments; data are the mean \pm SEM. $\boldsymbol{I}, \boldsymbol{J}$, Student's unpaired two-sided $t$ tests $(\boldsymbol{I} ; \boldsymbol{3}$ mice/group; $\boldsymbol{J}, 3$ and 5 mice/group). $\boldsymbol{K}-\boldsymbol{M}$, Two-way ANOVA with Bonferroni's post hoc tests ( $K$, vehicle $+\mathrm{PBS}$ and PLX $+\mathrm{PBS}, n=5$ mice/group; vehicle $+\mathrm{LPS}$ and PLX+LPS, $n=13$ mice/group; $L, n=9$ mice/group; $\boldsymbol{M}$, vehicle $+\mathrm{LPS}, n=6$ mice and PLX $+\mathrm{LPS}, n=4$ mice). $* p<0.05 ; * * p<0.01$, and $* * * p<0.01$. Scale bar: $\boldsymbol{H}$ (for $\boldsymbol{A}-\boldsymbol{H}), 200 \mu \mathrm{m}$.

develops throughout the spinal cord gray and white matter in wild-type mice after LPSx4 was significantly impaired in Cx3cr1Cre-Illr1 ${ }^{\mathrm{f} / \mathrm{f}}$ or Tie2-Cre-Illr1 $1^{\mathrm{fff}}$ mice (Fig. 11A-D). Loss of IL-1 signaling in microglia or endothelia also diminished the neuroprotective effects of LPSx4; significant neuron loss was evident in ventral horn gray matter of Cx3cr1-Cre-Illr $r^{f f /}$ and Tie2-Cre-Illr $\mathrm{f}^{\mathrm{fff}}$ mice relative to wild-type mice (Fig. $11 E-H$ ). Interestingly, however, although loss of IL-1 signaling in microglia or endothelia cells reversed the neuroprotective effects of LPSx4, this treatment still protected mice from developing paralysis after ISCI. In fact, openfield locomotor function was not visibly impaired in either Cx3cr1-

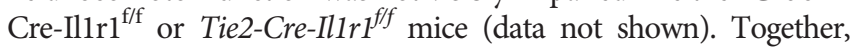
these data indicate that IL-1-dependent microglia-endothelia cross talk is necessary to cause reactive microgliosis and to achieve 

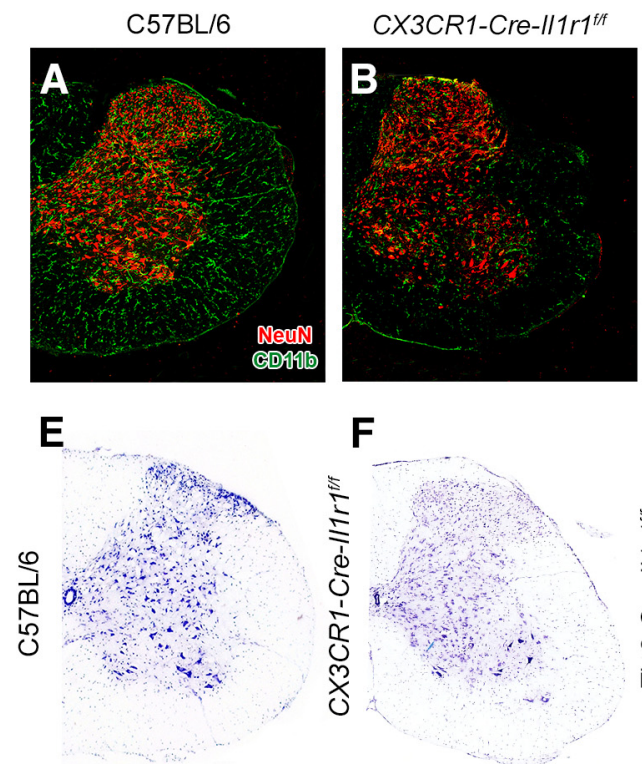
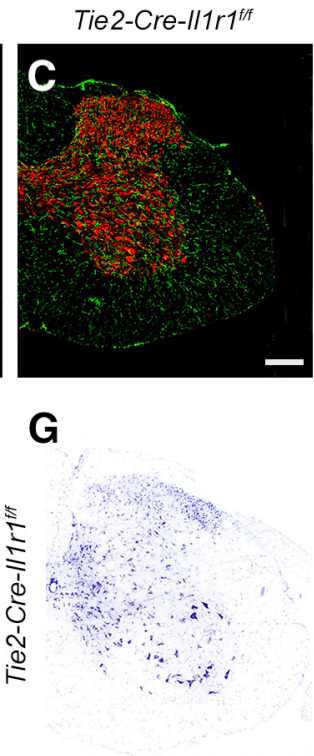
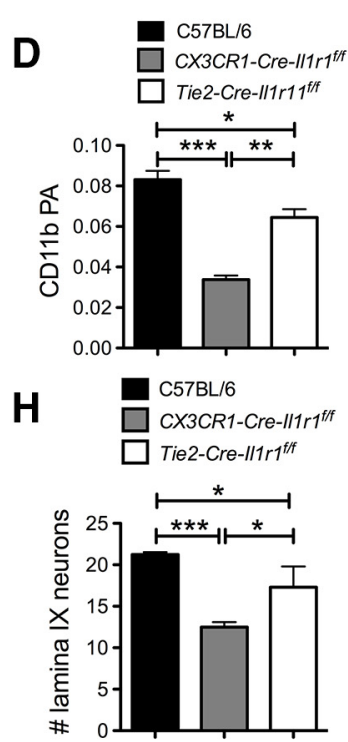

Figure 11. IL-1-dependent endothelial-microglial cross talk contributes to LPSX4-mediated neuroprotection. $A-C, E-G$, Representative cross sections of ischemic lumbar spinal cords of

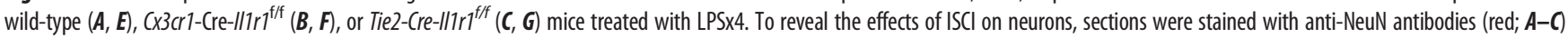
or cresyl violet $(\boldsymbol{E}-\boldsymbol{G})$. D, Loss of IL-1R1 in microglia or endothelia impairs the ability of LPSX4 to elicit reactive inflammation; this effect is most profound when IL-1-dependent signaling is abolished in microglia (compare CD11b; $\boldsymbol{B}, \boldsymbol{C}$, green labeling). cresyl violet stains show an obvious loss of neurons in ventral horn when IL-1R1 is specifically deleted from microglia (compare $\boldsymbol{E}, \boldsymbol{F}$ ) or endothelial cells (compare $\boldsymbol{E}, \boldsymbol{G}$ ). $\boldsymbol{H}$, Quantification of laminae IX motor neurons reveals loss of LPSX4-mediated neuroprotection when IL-1R1 is deleted from microglia or endothelial cells.

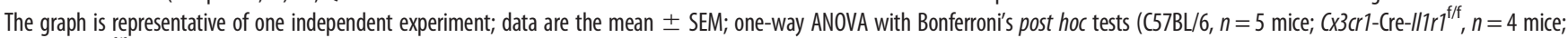
Tie2-Cre-II1r $r^{f / f}, n=2$ mice). $* p<0.05, * * p<0.01, * * * p<0.001$. Scale bar: $\mathbf{C}($ for $\boldsymbol{A}-\mathbf{G}), 200 \mu \mathrm{m}$.

optimal LPSx4-mediated neuroprotection after ISCI. However, LPSx4 may trigger additional neuroprotective programs in microglia that are IL-1 independent.

\section{Discussion}

Microglia regulate plasticity and immune surveillance throughout the healthy and diseased CNS. Since microglia are ubiquitous throughout the parenchyma and respond rapidly to cues in their microenvironment, it would be advantageous if the repair functions of these cells could be mobilized en masse to promote CNS repair or limit tissue damage caused by trauma or disease. LPS has long been known as a preconditioning stimulus that can protect the brain from ischemic injury, in part through the activation of microglia (Rosenzweig et al., 2004; Hickey et al., 2011; Chen et al., 2012). However, whether LPS can elicit neuroprotective microglia in the spinal cord without causing concurrent injury has not been determined. Here, we show that LPSx 4 elicits reactive spinal cord microglia defined by dramatic changes in morphology, increased production of IL-1, and enhanced proliferation. Importantly, these LPS-induced changes occur without triggering leukocyte recruitment or neuropathology. This reactive microglial response requires signals from spinal cord endothelial cells which first sense circulating LPS. Reactive microglia can then produce IL-1, which activates endothelia via IL-1R1mediated signaling. This paracrine signaling network amplifies a neuroprotective microglia network that confers optimal protection against neuronal death and paralysis in a mouse model of ISCI.

LPSx4 elicits a reactive spinal cord microglia response marked by morphologic transformation and proliferation LPS induces morphologic changes in brain microglia and increases their ability to produce cytokines and reactive oxygen species (Breder et al., 1994; Henry et al., 2009; Marsh et al., 2009a; Chen et al., 2012). These effects have been attributed to the activation of TLR4, and, to a lesser extent, CR3, CD14, and scavenger receptor A (Wright et al., 1990; Flaherty et al., 1997; Haworth et al., 1997; Zhang et al., 2014a). However, unlike the brain, where LPS diffuses into the neural parenchyma through leaky endothelial cells in the circumventricular organs and then directly activates microglial TLR4, LPS cannot cross the bloodspinal cord barrier (Banks and Robinson, 2010). Therefore, in the intact spinal cord, LPS must activate microglia indirectly via cross talk with other cells. Since TLR4 is expressed at high levels in the endothelial lumen, endothelia are likely to be the first cells that bind LPS (Mallard, 2012). Consistent with this hypothesis, the most robust response to LPSx4 was observed on perivascular microglia in the gray matter of the cervical and lumbar enlargements, which are more densely vascularized than thoracic spinal segments (Mautes et al., 2000). A major cytokine associated with the induction of reactive microglia was IL-1; reactive microgliosis was reduced in the absence of IL- $1 \alpha$ or IL- $1 \beta$. IL- 1 is considered a short-range communication molecule that acts predominantly in an autocrine or paracrine manner (Bruttger et al., 2015). IL-1 can stimulate cells with a low receptor number $(<100 /$ cell $)$ by initiating intracellular NF- $\kappa$ B cascades (Rothwell and Luheshi, 2000). Thus, IL-1-mediated intracellular signal amplification would explain progressively increasing microglia/endothelial responses with each successive LPS injection.

\section{How does LPS 4 confer neuroprotection?}

Given that endotoxin (LPS) causes vasodilation, one might predict that serial LPS injections could protect the spinal cord from ischemic injury by increasing blood flow through spinal collaterals. However, although LPS causes vasodilation, it also causes profound systemic hypotension, which would reduce spinal cord perfusion pressure and exacerbate, rather than reduce, spinal cord pathology. This is what occurred in a canine model of spinal 
cord ischemia when nitroprusside, a potent vasodilatory agent injected at the time of the aortic cross clamp, alleviated systemic hypertension caused by the cross-clamp procedure, but in doing so, the drug significantly reduced spinal cord perfusion pressure (Shine and Nugent, 1990). Instead, a more likely explanation for how LPS confers protection from ISCI is by maintaining integrity of the blood-spinal cord barrier. Recent data indicate that systemic injections of LPS can trigger CCR5-dependent recruitment of microglia to brain endothelia, and this increases the expression of endothelial tight-junction proteins (Haruwaka et al., 2019). Although we did not evaluate tight-junction proteins after ISCI, LPSx4 consistently promotes microglia-endothelia coupling in the spinal cord and also abolished vascular injury caused by ISCI (as determined by fibrinogen labeling).

Other mechanisms of LPSx4-mediated protection must also be considered in future studies, including the role played by pattern recognition receptors expressed by endothelia and/or microglia. In experimental models of ischemic brain injury, the neuroprotective effects of LPS preconditioning have been linked to TLR activation and the downstream synthesis of select inflammatory cytokines (Ahmed et al., 2000; Rosenzweig et al., 2004; Marsh et al., 2009b; Larochelle et al., 2015). It is unclear which cytokines are required. For example, blocking TNF, but not IL-1, inhibited the neuroprotective effects of LPS in a model of cerebral ischemia (Tasaki et al., 1997). In the same model, intraventricular delivery of TNF or interferon- $\beta$ alone recapitulated the protective effects of LPS, whereas intravenous or intraperitoneal injection of TNF did not (Nawashiro et al., 1997; Marsh et al., 2009b).

In spinal cord, the benefits of LPS preconditioning have been described only in the context of traumatic SCI (Hayakawa et al., 2014; Li et al., 2014, 2016). Because traumatic SCI cannot be predicted, preconditioning is of little clinical value in this context. However, preconditioning is a viable preventative therapy for planned surgeries, notably aortic aneurysm repair, where ISCI is a common complication (Rosenthal, 1999; Awad et al., 2017). Data in this report indicate that LPS-induced priming of IL-1-dependent microglia-endothelia cross talk protects the spinal cord from ischemic injury. Future studies are needed to reveal the cadre of neuroprotective cellular and molecular cascades that are initiated downstream of microglial-endothelia activation. For example, microglia-derived cytokines, including IL-1, can increase neuronal expression of neuroprotective proteins including Bcl-2, MnSOD, and Nrf2 (Tamatani et al., 1999; Wilde et al., 2000; Li et al., 2016). Compensatory anti-inflammatory cascades also are expected to be triggered as a result of the reactive microglia response. After IL- $1 \beta$ is released, its biological effects are tightly regulated by production of IL-1RA, soluble IL-1R1 (sIL1R1), sIL-1R2, and sIL-1RAcP (Allan et al., 2005). The enhanced expression of these inhibitors at the time of ischemic insult undoubtedly protects against toxic neuroinflammatory cascades.

Microglia-dependent, IL-1-independent neuroprotective mechanisms are also suspected. Indeed, in the absence of microglia, ISCI caused notable loss of spinal cord ventral horn motor neurons and neurologic impairment. Neuron loss was also observed after ISCI when IL-1R was deleted from microglia; however, hindlimb paralysis did not develop in these mice, suggesting that either a threshold of neuron loss is necessary before hindlimb motor function is impaired or that LPSx4 elicits additional neuroprotective programs in microglia that are IL-1 independent. For example, reactive microglia primed by LPS could change motor neuron excitability. In the brain, microglia activated by LPS ensheath cortical neurons, displacing presynaptic terminals from neuronal perikarya (Paolicelli et al.,
2011; Chen et al., 2012). This LPS-induced "synaptic stripping” was found to protect injured cortical neurons by specifically removing inhibitory GABAergic nerve terminals, leading to upregulation of antiapoptotic and growth-associated molecules (Hardingham et al., 2002; Hossain-Ibrahim et al., 2006; Chen et al., 2012, 2014; Gao et al., 2014). In the spinal cord, LPSx4 also enhances the number of reactive microglia that abut spinal motor neurons. It is expected that any meaningful neuroprotection conferred by perineuronal microglia would require multiple systemic injections of LPS since consistent intraspinal reactive microgliosis was not achieved unless mice received four daily systemic injections of LPS.

\section{Optimizing the therapeutic window and determining the requirements for reprogramming microglia for neuroprotection}

In the present study, mice were injected with four doses of LPS before ISCI. It is not known whether LPSx 4 would still confer protection to the spinal cord if it were started after ISCI. It is also not known whether reactive spinal cord microglia primed by LPSx 4 would maintain their neuroprotective phenotype weeks or months after stimulation. Since microglia are long lived cells, it is important to know whether they can be imprinted with molecular "memories," akin to how conventional vaccinations boost the functional potential of adaptive immune cells. Recent data indicate that repeat systemic injections of LPS can induce training or tolerance in brain microglia (i.e., different forms of "innate immune memory" that are dependent on the number of successive LPS injections; Wendeln et al., 2018). One or two consecutive systemic injections of LPS induces training marked by exaggerated production of inflammatory cytokines in the brain. Conversely, three or four LPS injections induce tolerance. Trained and tolerized microglia have unique epigenetic and transcriptomic signatures and when these distinct microglia phenotypes were activated in models of Alzheimer's disease or stroke, they differentially affected brain pathology_trained microglia exacerbated pathology while tolerized microglia conferred protection. Given that endotoxin has been proposed as a trigger for neurodegenerative disease (Brown, 2019), it is unlikely that, despite its utility to elicit neuroprotection, it would be widely accepted as a preventative therapy, even for individuals who are at higher risk of acquiring a CNS injury because of an elective surgery, participation in extreme or contact sports, or serving in the military. Instead, systemic injections of cytokines and other widely used vaccines (e.g., BCG) can also trigger innate immune memory and might represent viable therapeutic strategies, especially if they trigger epigenetic and transcriptomic changes in spinal cord microglia that mirror the effects of LPSx4.

In summary, like in the brain, LPSx 4 is a robust and reproducible tool for triggering spinal cord neuroprotection-a response that involves IL-1-dependent cross talk between spinal cord microglia and endothelial cells. Continued use of this powerful research tool should help to reveal how to reprogram microglia to provide neuroprotection. This could have broad therapeutic implications that would benefit individuals at risk of developing intraspinal neuropathology.

\section{References}

Ahmed SH, He YY, Nassief A, Xu J, Xu XM, Hsu CY (2000) Effects of lipopolysaccharide priming on acute ischemic brain injury. Stroke 31:193199.

Allan SM, Tyrrell PJ, Rothwell NJ (2005) Interleukin-1 and neuronal injury. Nat Rev Immunol 5:629-640. 
Awad H, Ankeny DP, Guan Z, Wei P, McTigue DM, Popovich PG (2010) A mouse model of ischemic spinal cord injury with delayed paralysis caused by aortic cross-clamping. Anesthesiology 113:880-891.

Awad H, Ramadan ME, Sayed El HF, Tolpin DA, Tili E, Collard CD (2017) Spinal cord injury after thoracic endovascular aortic aneurysm repair. Can J Anaesth 64:1218-1235.

Banks WA, Robinson SM (2010) Minimal penetration of lipopolysaccharide across the murine blood-brain barrier. Brain Behav Immun 24:102-109.

Bartanusz V, Jezova D, Alajajian B, Digicaylioglu M (2011) The blood-spinal cord barrier: morphology and clinical implications. Ann Neurol 70:194206.

Basso DM, Fisher LC, Anderson AJ, Jakeman LB, McTigue DM, Popovich PG (2006) Basso Mouse Scale for locomotion detects differences in recovery after spinal cord injury in five common mouse strains. J Neurotrauma 23:635-659.

Bastien D, Bellver Landete V, Lessard M, Vallières $\mathrm{N}$, Champagne $\mathrm{M}$, Takashima A, Tremblay ME, Doyon Y, Lacroix S (2015) IL- $1 \alpha$ gene deletion protects oligodendrocytes after spinal cord injury through upregulation of the survival factor Tox3. J Neurosci 35:10715-10730.

Batchelor PE, Tan S, Wills TE, Porritt MJ, Howells DW (2008) Comparison of inflammation in the brain and spinal cord following mechanical injury. J Neurotrauma 25:1217-1225.

Bellver-Landete V, Bretheau F, Mailhot B, Vallières N, Lessard M, Janelle ME, Vernoux N, Tremblay ME, Fuehrmann T, Shoichet MS, Lacroix S (2019) Microglia are an essential component of the neuroprotective scar that forms after spinal cord injury. Nat Commun 10:518.

Breder CD, Hazuka C, Ghayur T, Klug C, Huginin M, Yasuda K, Teng M, Saper CB (1994) Regional induction of tumor necrosis factor alpha expression in the mouse brain after systemic lipopolysaccharide administration. Proc Natl Acad Sci U S A 91:11393-11397.

Brown GC (2019) The endotoxin hypothesis of neurodegeneration. J Neuroinflammation 16:180.

Bruttger J, Karram K, Wörtge S, Regen T, Marini F, Hoppmann N, Klein M, Blank T, Yona S, Wolf Y, Mack M, Pinteaux E, Müller W, Zipp F, Binder H, Bopp T, Prinz M, Jung S, Waisman A (2015) Genetic cell ablation reveals clusters of local self-renewing microglia in the mammalian central nervous system. Immunity 43:92-106.

Butovsky O, Jedrychowski MP, Moore CS, Cialic R, Lanser AJ, Gabriely G, Koeglsperger T, Dake B, Wu PM, Doykan CE, Fanek Z, Liu L, Chen Z, Rothstein JD, Ransohoff RM, Gygi SP, Antel JP, Weiner HL (2014) Identification of a unique TGF- $\beta$-dependent molecular and functional signature in microglia. Nat Neurosci 17:131-143.

Chen Z, Trapp BD (2016) Microglia and neuroprotection. J Neurochem 136 [Suppl 1]:10-17.

Chen Z, Jalabi W, Shpargel KB, Farabaugh KT, Dutta R, Yin X, Kidd GJ, Bergmann CC, Stohlman SA, Trapp BD (2012) Lipopolysaccharideinduced microglial activation and neuroprotection against experimental brain injury is independent of hematogenous TLR4. J Neurosci 32:11706-11715

Chen Z, Jalabi W, Hu W, Park HJ, Gale JT, Kidd GJ, Bernatowicz R, Gossman ZC, Chen JT, Dutta R, Trapp BD (2014) Microglial displacement of inhibitory synapses provides neuroprotection in the adult brain. Nat Commun 5:4486.

Dagher NN, Najafi AR, Kayala KM, Elmore MR, White TE, Medeiros R, West BL, Green KN (2015) Colony-stimulating factor 1 receptor inhibition prevents microglial plaque association and improves cognition in 3xTg-AD mice. J Neuroinflammation 12:139.

Elmore MR, Najafi AR, Koike MA, Dagher NN, Spangenberg EE, Rice RA, Kitazawa M, Matusow B, Nguyen H, West BL, Green KN (2014) Colonystimulating factor 1 receptor signaling is necessary for microglia viability, unmasking a microglia progenitor cell in the adult brain. Neuron 82:380397.

Flaherty SF, Golenbock DT, Milham FH, Ingalls RR (1997) CD11/CD18 leukocyte integrins: new signaling receptors for bacterial endotoxin. J Surg Res 73:85-89.

Gallyas F, Wolff JR, Böttcher H, Záborszky L (1980) A reliable method for demonstrating axonal degeneration shortly after axotomy. Stain Technol 55:291-297.

Gao F, Liu ZQ, Ren W, Jiang W (2014) Acute lipopolysaccharide exposure facilitates epileptiform activity via enhanced excitatory synaptic transmission and neuronal excitability in vitro. Neuropsychiatr Dis Treat $10: 1489-1495$.
Gensel JC, Wang Y, Guan Z, Beckwith KA, Braun KJ, Wei P, McTigue DM, Popovich PG (2015) Toll-like receptors and dectin-1, a C-type lectin receptor, trigger divergent functions in CNS macrophages. J Neurosci 35:9966-9976.

Godbout JP, Chen J, Abraham J, Richwine AF, Berg BM, Kelley KW, Johnson RW (2005) Exaggerated neuroinflammation and sickness behavior in aged mice following activation of the peripheral innate immune system. FASEB J 19:1329-1331.

Gravereaux EC, Faries PL, Burks JA, Latessa V, Spielvogel D, Hollier LH, Marin ML (2001) Risk of spinal cord ischemia after endograft repair of thoracic aortic aneurysms. J Vasc Surg 34:997-1003.

Haruwaka K, Ikegami A, Tachibana Y, Ohno N, Konishi H, Hashimoto A, Matsumoto M, Kato D, Ono R, Kiyama H, Moorhouse AJ, Nabekura J, Wake H (2019) Dual microglia effects on blood brain barrier permeability induced by systemic inflammation. Nat Commun 10:5816-5817.

Hayakawa K, Okazaki R, Morioka K, Nakamura K, Tanaka S, Ogata T (2014) Lipopolysaccharide preconditioning facilitates M2 activation of resident microglia after spinal cord injury. J Neurosci Res 92:1609-1800.

Hardingham GE, Fukunaga Y, Bading H (2002) Extrasynaptic NMDARs oppose synaptic NMDARs by triggering CREB shut-off and cell death pathways. Nat Neurosci 5:405-414.

Haworth R, Platt N, Keshav S, Hughes D, Darley E, Suzuki H, Kurihara Y, Kodama T, Gordon S (1997) The macrophage scavenger receptor type A is expressed by activated macrophages and protects the host against lethal endotoxic shock. J Exp Med 186:1431-1439.

Henry CJ, Huang Y, Wynne AM, Godbout JP (2009) Peripheral lipopolysaccharide (LPS) challenge promotes microglial hyperactivity in aged mice that is associated with exaggerated induction of both pro-inflammatory IL-1beta and anti-inflammatory IL-10 cytokines. Brain Behav Immun 23:309-317.

Hickey E, Shi H, Van Arsdell G, Askalan R (2011) Lipopolysaccharideinduced preconditioning against ischemic injury is associated with changes in toll-like receptor 4 expression in the rat developing brain. Pediatr Res 70:10-14.

Hoogland IC, Houbolt C, van Westerloo DJ, van Gool WA, van de Beek D (2015) Systemic inflammation and microglial activation: systematic review of animal experiments. J Neuroinflammation 12:114.

Horai R, Asano M, Sudo K, Kanuka H, Suzuki M, Nishihara M, Takahashi M, Iwakura Y (1998) Production of mice deficient in genes for interleukin (IL)-1, IL-1, IL-1/, and IL-1 receptor antagonist shows that IL-1 is crucial in turpentine-induced fever development and glucocorticoid secretion. J Exp Med 187:1463-1475.

Hossain-Ibrahim MK, Rezajooi K, MacNally JK, Mason MRJ, Lieberman AR, Anderson PN (2006) Effects of lipopolysaccharide-induced inflammation on expression of growth-associated genes by corticospinal neurons. BMC Neurosci 7:8

Huxtable AG, Smith SM, Vinit S, Watters JJ, Mitchell GS (2013) Systemic LPS induces spinal inflammatory gene expression and impairs phrenic long-term facilitation following acute intermittent hypoxia. J Appl Physiol (1985) 114:879-887.

Keren-Shaul H, Spinrad A, Weiner A, Matcovitch-Natan O, Dvir-Szternfeld R, Ulland TK, David E, Baruch K, Lara-Astaiso D, Toth B, Itzkovitz S, Colonna M, Schwartz M, Amit I (2017) A unique microglia type associated with restricting development of alzheimer's disease. Cell 169:12761290.e17.

Krasemann S, Madore C, Cialic R, Baufeld C, Calcagno N, El Fatimy R, Beckers L, O'Loughlin E, Xu Y, Fanek Z, Greco DJ, Smith ST, Tweet G, Humulock Z, Zrzavy T, Conde-Sanroman P, Gacias M, Weng Z, Chen $\mathrm{H}$, Tjon E, et al. (2017) The TREM2-APOE pathway drives the transcriptional phenotype of dysfunctional microglia in neurodegenerative diseases. Immunity 47:566-581.e9.

Lacroix S, Feinstein D, Rivest S (1998) The bacterial endotoxin lipopolysaccharide has the ability to target the brain in upregulating its membrane CD14 receptor within specific cellular populations. Brain Pathol 8:625640

Larochelle A, Bellavance M-A, Rivest S (2015) Role of adaptor protein MyD88 in TLR-mediated preconditioning and neuroprotection after acute excitotoxicity. Brain Behav Immun 46:221-231.

Lawson LJ, Perry VH, Dri P, Gordon S (1990) Heterogeneity in the distribution and morphology of microglia in the normal adult mouse brain. Neuroscience 39:151-170. 
Li W-C, Jiang R, Jiang D-M, Zhu F-C, Su B, Qiao B, Qi X-T (2014) Lipopolysaccharide preconditioning attenuates apoptotic processes and improves neuropathologic changes after spinal cord injury in rats. Int J Neurosci 124:585-592.

Li WC, Jiang DM, Li QX, Yao SP, Sun XR, Yang Y, Meng ZD, Liu W (2016) Lipopolysaccharide-induced preconditioning protects against traumatic spinal cord injury by upregulating Nrf2 expression in rats. Life Sciences $162: 14-20$

Liddelow SA, Guttenplan KA, Clarke LE, Bennett FC, Bohlen CJ, Schirmer L, Bennett ML, Münch AE, Chung W-S, Peterson TC, Wilton DK, Frouin A, Napier BA, Panicker N, Kumar M, Buckwalter MS, Rowitch DH, Dawson VL, Dawson TM, Stevens B, et al. (2017) Neurotoxic reactive astrocytes are induced by activated microglia. Nature 541:481-487.

Liu X, Quan N (2018) Microglia and CNS interleukin-1: beyond immunological concepts. Front Neurol 9:8.

Liu X, Yamashita T, Chen Q, Belevych N, Mckim DB, Tarr AJ, Coppola V, Nath N, Nemeth DP, Syed ZW, Sheridan JF, Godbout JP, Zuo J, Quan N (2015) Interleukin 1 type 1 receptor restore: a genetic mouse model for studying interleukin 1 receptor-mediated effects in specific cell types. J Neurosci 35:2860-2870.

Liu X, Nemeth DP, McKim DB, Zhu L, DiSabato DJ, Berdysz O, Gorantla G, Oliver B, Witcher KG, Wang Y, Negray CE, Vegesna RS, Sheridan JF, Godbout JP, Robson MJ, Blakely RD, Popovich PG, Bilbo SD, Quan N (2019) Cell-type-specific interleukin 1 receptor 1 signaling in the brain regulates distinct neuroimmune activities. Immunity 50:317-333.e6.

Lloyd AF, Davies CL, Holloway RK, Labrak Y, Ireland G, Carradori D, Dillenburg A, Borger E, Soong D, Richardson JC, Kuhlmann T, Williams A, Pollard JW, des Rieux A, Priller J, Miron VE (2019) Central nervous system regeneration is driven by microglia necroptosis and repopulation. Nat Neurosci 22:1046-1052.

Mallard C (2012) Innate immune regulation by toll-like receptors in the brain. ISRN Neurol 2012:701950.

Marsh B, Stevens SL, Packard AE, Gopalan B, Hunter B, Leung PY, Harrington CA, Stenzel-Poore MP (2009a) Systemic lipopolysaccharide protects the brain from ischemic injury by reprogramming the response of the brain to stroke: a critical role for IRF3. J Neurosci 29:9839-9849.

Marsh BJ, Williams-Karnesky RL, Stenzel-Poore MP (2009b) Toll-like receptor signaling in endogenous neuroprotection and stroke. Neuroscience 158:1007-1020.

Matsushima H, Ogawa Y, Miyazaki T, Tanaka H, Nishibu A, Takashima A (2010) Intravital imaging of IL-1beta production in skin. J Invest Dermatol 130:1571-1580.

Mautes AE, Weinzierl MR, Donovan F, Noble LJ (2000) Vascular events after spinal cord injury: contribution to secondary pathogenesis. Phys Ther 80:673-687.

Nawashiro H, Tasaki K, Ruetzler CA, Hallenbeck JM (1997) TNF- $\alpha$ pretreatment induces protective effects against focal cerebral ischemia in mice. J Cereb Blood Flow Metab 17:483-490.

Nimmerjahn A, Kirchhoff F, Helmchen F (2005) Resting microglial cells are highly dynamic surveillants of brain parenchyma in vivo. Science 308:1314-1318.

Norden DM, Muccigrosso MM, Godbout JP (2015) Microglial priming and enhanced reactivity to secondary insult in aging, and traumatic CNS injury, and neurodegenerative disease. Neuropharmacology 96:29-41.

Panov AV, Kubalik N, Zinchenko N, Ridings DM, Radoff DA, Hemendinger R, Brooks BR, Bonkovsky HL (2011) Metabolic and functional differences between brain and spinal cord mitochondria underlie different predisposition to pathology. Am J Physiol Regul Integr Comp Physiol 300: R844-R854.

Paolicelli RC, Bolasco G, Pagani F, Maggi L, Scianni M, Panzanelli P, Giustetto M, Ferreira TA, Guiducci E, Dumas L, Ragozzino D, Gross CT (2011) Synaptic pruning by microglia is necessary for normal brain development. Science 333:1456-1458.

Qin L, Wu X, Block ML, Liu Y, Breese GR, Hong JS, Knapp DJ, Crews FT (2007) Systemic LPS causes chronic neuroinflammation and progressive neurodegeneration. Glia 55:453-462.

Rosenthal D (1999) Spinal cord ischemia after abdominal aortic operation: is it preventable? J Vasc Surg 30:391-397.
Rosenzweig HL, Lessov NS, Henshall DC, Minami M, Simon RP, StenzelPoore MP (2004) Endotoxin preconditioning prevents cellular inflammatory response during ischemic neuroprotection in mice. Stroke 35:25762581.

Rothwell NJ, Luheshi GN (2000) Interleukin 1 in the brain: biology, pathology and therapeutic target. Trends Neurosci 23:618-625.

Schmittgen TD, Livak KJ (2008) Analyzing real-time PCR data by the comparative $\mathrm{C}(\mathrm{T})$ method. Nat Protoc 3:1101-1108.

Schnell L, Fearn S, Klassen H, Schwab ME, Perry VH (1999a) Acute inflammatory responses to mechanical lesions in the CNS: differences between brain and spinal cord. Eur J Neurosci 11:3648-3658.

Schnell L, Fearn S, Schwab ME, Perry VH, Anthony DC (1999b) Cytokineinduced acute inflammation in the brain and spinal cord. J Neuropathol Exp Neurol 58:245-254

Shine T, Nugent M (1990) Sodium nitroprusside decreases spinal cord perfusion pressure during descending thoracic aortic cross-clamping in the dog. J Cardiothorac Anesth 4:185-193.

Spangenberg EE, Lee RJ, Najafi AR, Rice RA, Elmore MR, Blurton-Jones M, West BL, Green KN (2016) Eliminating microglia in Alzheimer's mice prevents neuronal loss without modulating amyloid- $\beta$ pathology. Brain 139:1265-1281.

Stevens SL, Leung PY, Vartanian KB, Gopalan B, Yang T, Simon RP, StenzelPoore MP (2011) Multiple preconditioning paradigms converge on interferon regulatory factor-dependent signaling to promote tolerance to ischemic brain injury. J Neurosci 31:8456-8463.

Szalay G, Martinecz B, Lénárt N, Környei Z, Orsolits B, Judák L, Császár E, Fekete R, West BL, Katona G, Rózsa B, Dénes A (2016) Microglia protect against brain injury and their selective elimination dysregulates neuronal network activity after stroke. Nat Commun 7:11499.

Tamatani M, Che YH, Matsuzaki H, Ogawa S, Okado H, Miyake S, Mizuno T, Tohyama M (1999) Tumor necrosis factor induces Bcl-2 and Bcl-x expression through NF kappa B activation in primary hippocampal neurons. J Biol Chem 274:8531-8538.

Tasaki K, Ruetzler CA, Ohtsuki T, Martin D, Nawashiro H, Hallenbeck JM (1997) Lipopolysaccharide pre-treatment induces resistance against subsequent focal cerebral ischemic damage in spontaneously hypertensive rats. Brain Res 748:267-270.

Torres-Espín A, Forero J, Fenrich KK, Lucas-Osma AM, Krajacic A, Schmidt E, Vavrek R, Raposo P, Bennett DJ, Popovich PG, Fouad K (2018) Eliciting inflammation enables successful rehabilitative training in chronic spinal cord injury. Brain 141:1946-1962.

Wendeln A-C, Degenhardt K, Kaurani L, Gertig M, Ulas T, Jain G, Wagner J, Häsler LM, Wild K, Skodras A, Blank T, Staszewski O, Datta M, Centeno TP, Capece V, Islam MR, Kerimoglu C, Staufenbiel M, Schultze JL, Beyer $\mathrm{M}$, et al. (2018) Innate immune memory in the brain shapes neurological disease hallmarks. Nature 556:332-338.

Wilde GJC, Pringle AK, Sundstrom LE, Mann DA, Iannotti F (2000) Attenuation and augmentation of ischaemia-related neuronal death by tumour necrosis factor-alpha in vitro. Eur J Neurosci 12:3863-3870.

Wright SD, Ramos RA, Tobias PS, Ulevitch RJ, Mathison JC (1990) CD14, a receptor for complexes of lipopolysaccharide (LPS) and LPS binding protein. Science 249:1431-1433.

Yang S, Li X, You C, Wang T, Zhao J (2014) Lipopolysaccharide preconditioning induces neuroprotection against early brain injury after experimental subarachnoid hemorrhage. Turk Neurosurg 24:839-843.

Zhang B, Gensel JC (2014) Is neuroinflammation in the injured spinal cord different than in the brain? Examining intrinsic differences between the brain and spinal cord. Exp Neurol 258:112-120.

Zhang G, Ghosh S (2001) Toll-like receptor-mediated NF-kappaB activation: a phylogenetically conserved paradigm in innate immunity. J Clin Invest 107:13-19.

Zhang JF, Malik A, Choi HB, Ko RWY, Dissing-Olesen L, MacVicar BA (2014a) Microglial CR3 activation triggers long-term synaptic depression in the hippocampus via NADPH oxidase. Neuron 82:195-207.

Zhang Y, Chen K, Sloan SA, Bennett ML, Scholze AR, O'Keeffe S, Phatnani HP, Guarnieri P, Caneda C, Ruderisch N, Deng S, Liddelow SA, Zhang C, Daneman R, Maniatis T, Barres BA, Wu JQ (2014b) An RNAsequencing transcriptome and splicing database of glia, neurons, and vascular cells of the cerebral cortex. J Neurosci 34:11929-11947. 